\title{
The Ice Selective Inlet: a novel technique for exclusive extraction of pristine ice crystals in mixed-phase clouds
}

\author{
P. Kupiszewski ${ }^{1}$, E. Weingartner ${ }^{1, a}$, P. Vochezer $^{2}$, M. Schnaiter ${ }^{2}$, A. Bigi ${ }^{3}$, M. Gysel ${ }^{1}$, B. Rosati ${ }^{1}$, E. Toprak ${ }^{2}$, \\ S. Mertes ${ }^{4}$, and U. Baltensperger ${ }^{1}$ \\ ${ }^{1}$ Laboratory of Atmospheric Chemistry, Paul Scherrer Institute, Villigen PSI, Switzerland \\ ${ }^{2}$ Institute for Meteorology and Climate Research, Karlsruhe Institute of Technology, Karlsruhe, Germany \\ ${ }^{3}$ Department of Engineering "Enzo Ferrari”, University of Modena and Reggio Emilia, Modena, Italy \\ ${ }^{4}$ Leibniz Institute for Tropospheric Research, Leipzig, Germany \\ ${ }^{a}$ now at: Institute for Aerosol and Sensor Technology, University of Applied Sciences, Windisch, Switzerland
}

Correspondence to: E. Weingartner (ernest.weingartner@fhnw.ch)

Received: 19 November 2014 - Published in Atmos. Meas. Tech. Discuss.: 12 December 2014

Revised: 8 June 2015 - Accepted: 20 July 2015 - Published: 3 August 2015

\begin{abstract}
Climate predictions are affected by high uncertainties partially due to an insufficient knowledge of aerosolcloud interactions. One of the poorly understood processes is formation of mixed-phase clouds (MPCs) via heterogeneous ice nucleation. Field measurements of the atmospheric ice phase in MPCs are challenging due to the presence of much more numerous liquid droplets. The Ice Selective Inlet (ISI), presented in this paper, is a novel inlet designed to selectively sample pristine ice crystals in mixed-phase clouds and extract the ice residual particles contained within the crystals for physical and chemical characterization. Using a modular setup composed of a cyclone impactor, droplet evaporation unit and pumped counterflow virtual impactor (PCVI), the ISI segregates particles based on their inertia and phase, exclusively extracting small ice particles between 5 and $20 \mu \mathrm{m}$ in diameter. The setup also includes optical particle spectrometers for analysis of the number size distribution and shape of the sampled hydrometeors.

The novelty of the ISI is a droplet evaporation unit, which separates liquid droplets and ice crystals in the airborne state, thus avoiding physical impaction of the hydrometeors and limiting potential artefacts. The design and validation of the droplet evaporation unit is based on modelling studies of droplet evaporation rates and computational fluid dynamics simulations of gas and particle flows through the unit. Prior to deployment in the field, an inter-comparison of the optical particle size spectrometers and a characterization of the transmission efficiency of the PCVI was conducted in the
\end{abstract}

laboratory. The ISI was subsequently deployed during the Cloud and Aerosol Characterization Experiment (CLACE) 2013 and 2014 - two extensive international field campaigns encompassing comprehensive measurements of cloud microphysics, as well as bulk aerosol, ice residual and ice nuclei properties. The campaigns provided an important opportunity for a proof of concept of the inlet design. In this work we present the setup of the ISI, including the modelling and laboratory characterization of its components, as well as field measurements demonstrating the ISI performance and validating the working principle of the inlet. Finally, measurements of biological aerosol during a Saharan dust event (SDE) are presented, showing a first indication of enrichment of bio-material in sub- $2 \mu \mathrm{m}$ ice residuals.

\section{Introduction}

High uncertainties in future climate predictions arise from insufficient knowledge of the interaction of clouds with visible (solar) and infrared (terrestrial) radiation. The optical properties, cloud lifetime and cloud cover are strongly influenced by the ability of atmospheric aerosol particles to act as cloud condensation nuclei (CCN) or ice nuclei (IN) (Lohmann and Feichter, 2005; Penner, 2004). These aerosol-cloud interactions have been recognized as the greatest sources of uncertainty in the anthropogenic effective radiative forcing (Myhre et al., 2013) and, thus, in assessing human impact on cli- 
mate. Up to now, the climate-relevant properties of clouds and their formation processes are still poorly understood, particularly those of mixed-phase clouds where supercooled liquid droplets and ice crystals coexist. Previous research has found that the cloud radiative properties strongly depend on the cloud ice mass fraction (Sun and Shine, 1994), which is influenced by the abundance of IN. Increased IN concentrations are also thought to enhance precipitation in mixed-phase clouds (Pruppacher and Klett, 1997), thus causing a decrease in cloud lifetime and cloud cover, and affecting the radiative budget of the atmosphere (Lohmann and $\mathrm{Fe}$ ichter, 2005). Meanwhile, the physical and chemical properties of atmospherically relevant IN are not well known. For example, it is unclear whether anthropogenic emissions of black carbon (BC) contribute significantly to IN number, in addition to natural IN such as mineral dust or bacteria. Field measurements have not been conclusive as to the role of BC. For example, based on measurements at the high-altitude research station Jungfraujoch, Cozic et al. (2008) found enrichment of BC in ice residuals (IRs) extracted from small ice crystals, while Chou et al. (2011) found no correlation between IN number concentration and BC mass concentration. Should BC be an atmospherically important IN, the increase in aerosol concentrations since pre-industrial times would be responsible for a glaciation indirect effect on clouds. Cloud glaciation would be more frequent in the present day, resulting in a higher precipitation probability of a cloud (due to the rapid growth of ice crystals at the expense of supercooled droplets via the Wegener-Bergeron-Findeisen process). This in turn could have reduced the cloud fraction, thus leading to an increase in absorption of shortwave radiation by the Earth-atmosphere system (Lohmann, 2002).

The interaction between aerosols and mixed-phase clouds (MPCs) is presently poorly understood, and field studies on the physical and chemical characteristics of IN are sparse (Cantrell and Heymsfield, 2005). A number of studies on IR properties have been conducted in high-altitude ice clouds using a counterflow virtual impactor (CVI) to separate interstitial aerosol particles and ice crystals (e.g. Cziczo et al., 2013; Prenni et al., 2007; Twohy and Poellot, 2005). However, field measurements of ice residuals in mixed-phase clouds are hampered by difficulties with extracting the relatively few ice crystals found in MPCs and separating them from the much more numerous supercooled liquid droplets. This challenge is further exacerbated by the fact that small, freshly nucleated ice crystals have similar aerodynamic diameters to the liquid cloud droplets and thus cannot be separated using conventional impactor techniques. To the best of the authors' knowledge, prior to this work only one groundbased inlet for sampling ice crystals in MPCs had been successfully operated and described in the literature. This socalled Ice Counterflow Virtual Impactor (Ice-CVI) (Mertes et al., 2007) employs a series of modules to remove precipitating particles, particles larger than $20 \mu \mathrm{m}$, supercooled droplets and interstitial particles. Separation of the liquid and ice phases is achieved using a two-stage impactor consisting of cool plates on which hydrometeors are impinged. Upon impact the droplets freeze on the surface of the plate, while the ice crystals bounce off.

In view of the difficulties in measurements of the ice phase in MPCs, the paucity of inlet systems suitable for MPC characterization, and the resulting scarcity of data from the field, there is a great need for development of novel instrumentation. In this paper we describe the Ice Selective Inlet (ISI), which was designed and developed to extract ice crystals in MPCs and is conceptually inspired by the Ice-CVI (Mertes et al., 2007). The ISI separates small pristine ice particles (their residuals are considered representative of the original IN) from supercooled liquid droplets, interstitial particles and potentially contaminated large ice crystals, and it extracts the ice residuals contained within the small ice crystals for physical and chemical characterization. The inlet represents a novel tool for the in situ investigation of MPCs, and the optical particle spectrometers contained within the inlet deliver information that is not available by means of any other existing inlet. The ISI was successfully deployed and tested in the field for the first time as part of the Cloud and Aerosol Characterization Experiment (CLACE) 2013 - an international campaign encompassing comprehensive measurements of cloud microphysics, as well as bulk aerosol, ice residual and ice nuclei properties (Lloyd et al., 2015; Schenk et al., 2014; Schmidt et al., 2015; Vochezer et al., 2015; Worringen et al., 2015). The ISI was modified following CLACE 2013 and subsequently re-deployed during CLACE 2014. In this work we present the setup of the ISI, including the modelling and laboratory characterization of its components, as well as measurements from the CLACE 2013 and 2014 field campaigns, validating the operating principle of the ISI. Finally, an analysis of bioaerosol measurements during a Saharan dust event (SDE) is presented, showing enrichment of bio-material in sub- $2 \mu \mathrm{m}$ ice residuals.

\section{Setup and characterization of the Ice Selective Inlet and additional instrumentation}

\subsection{Ice Selective Inlet setup}

The design of the Ice Selective Inlet (Fig. 1) is inspired by the Ice-CVI inlet (Mertes et al., 2007), albeit with some key differences. Foremost amongst these is the technique used to separate ice crystals from supercooled droplets. In the ISI the separation takes place in the airborne state, as opposed to physical impaction on cool plates, thus limiting potential artefacts, e.g. from ice crystal break-up or abrasion of the inlet surface coating. The working principle of the droplet evaporation unit, which is used to remove supercooled liquid droplets sampled by the ISI, is described in detail in Sect. 2.4. The purpose of the ISI is to extract small $(5-20 \mu \mathrm{m})$ ice crystals from mixed-phase clouds. These crystals are assumed to 


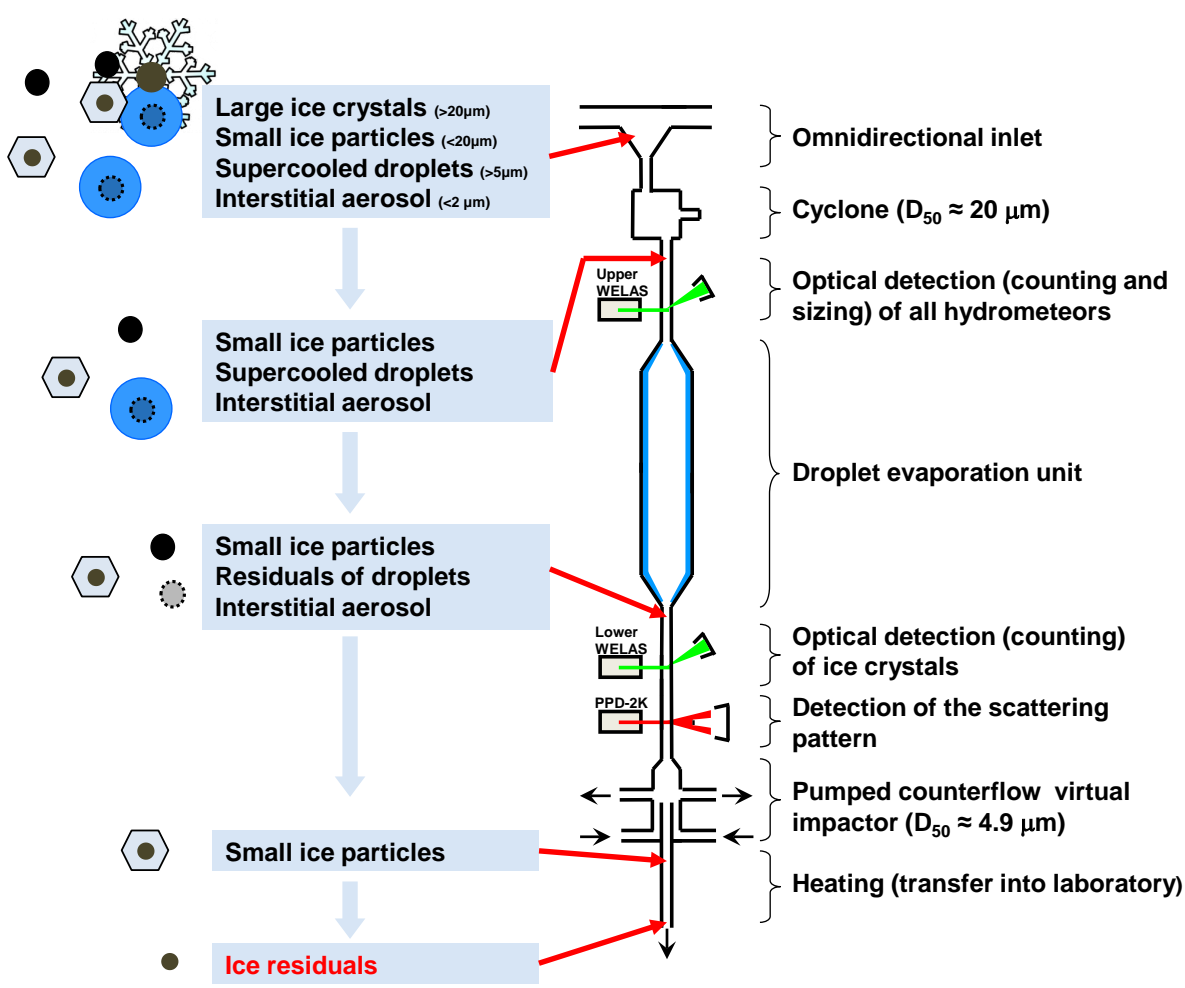

Figure 1. Sketch of the Ice Selective Inlet. The particulate matter contained within the sample flow is visualized on the left-hand side of the figure.

have formed via heterogeneous nucleation and, subsequently, to have grown via vapour diffusion. The ice residuals contained within can thus be considered representative of the original ice nuclei.

Sampling by the ISI can be divided into the following steps: cloud air is aspirated through the ISI at a flow rate of $7 \mathrm{~L} \mathrm{~min}^{-1}$. An omnidirectional inlet, shielded from above and a custom-made Sharp Cut Cyclone (BGI Inc., USA), with a $D_{50}$ (i.e. the aerodynamic diameter at which $50 \%$ of the particles are removed from the sample flow and $50 \%$ are transmitted) of $20 \mu \mathrm{m}$ ensure that precipitating particles and ice crystals larger than $20 \mu \mathrm{m}$ in aerodynamic diameter are removed from the sample flow. It is important to remove the larger ice particles because the residuals contained within larger ice crystals may be unrepresentative of the original ice nuclei. The larger ice crystals have not necessarily grown by water vapour diffusion, as is assumed for small ice crystals; instead they may have grown by riming (i.e. capture and freezing of supercooled liquid droplets on falling ice crystals; Mosimann et al., 1994), and thus they could also contain CCN from the captured droplets. Furthermore, uptake of gases on ice crystals may take place (e.g. Kärcher and Basko, 2004; Marécal et al., 2010), thus contaminating the ice residuals. Larger, more-aged ice particles would be more susceptible to contamination via this pathway than small, fresh ice crystals. The performance characteristics of the omnidirectional inlet and cyclone are presented in Sect. 2.3.
Hydrometeor number size distributions are measured upstream and downstream of the droplet evaporation unit using two WELAS 2500 aerosol sensor systems (white-light aerosol spectrometer; Palas GmbH, Germany). Each sensor system contains a WELAS 2500 sensor and a Promo 2000 control unit. The latter houses the white light source and a photomultiplier tube (PMT) where the light scattered at an angle of $78-102^{\circ}$ by particles passing through the sensing volume is measured. Optical fibres are used to transmit light between the Promo 2000 and the WELAS 2500. The use of white light is important in helping to circumvent difficulties in unambiguous particle sizing which arise when using a laser spectrometer due to the strongly non-monotonic relationship between the intensity of scattered light and particle diameter (Heim et al., 2008). Furthermore, decoupling of the light source and scattered light detector from the measuring volume using optical fibres is an important feature which prevents heat transfer to the ISI system. For an in-depth and extensive description of the measurement principle of WELAS sensors the reader is referred to Heim et al. (2008) and Rosati et al. (2015).

Downstream of the WELAS sensors the PPD-2K, a modified version of the Particle Phase Discriminator (Kaye et al., 2008), custom-built and adapted for use within the ISI inlet, is mounted. The modifications of the PPD-2K compared to the instrument described in Kaye et al. (2008) are the replacement of the in-board PC by an external laptop and the use of 
polyether ether ketone (PEEK) encapsulations for the inlet and outlet nozzle of the instrument. With these modifications the heat transfer to the sample flow is minimized and the operation of a computer under harsh conditions is avoided. The PPD-2K acquires high-resolution scattering patterns of individual cloud particles. In order to calibrate the sizing of the instrument, scattering patterns of droplets are selected and exact Mie solutions are fitted to these patterns. Thus, the PPD-2K provides an optical diameter for all sampled particles, which is equivalent to the scattering of a droplet in $5-26^{\circ}$ forward direction. The scattering patterns contain information about microphysical properties of individual cloud particles such as particle size, shape and surface roughness. Thus, the analysis of the PPD- $2 \mathrm{~K}$ scattering patterns enables a highly sensitive distinction between water droplets and ice particles and provides an invaluable check of the droplet evaporation unit operation. The scattering patterns are recorded starting from the detection limit of around $5 \mu \mathrm{m}$. The analysis procedure as well as a detailed characterization of the instrument is the subject of a separate publication (Vochezer et al., 2015). In addition to the scattering patterns, the PPD-2K generates a particle number size distribution based on the forward scattering signal.

Downstream of the PPD-2K, interstitial particles and residual particles released from the droplets in the droplet evaporation unit are removed from the sample flow with the use of the commercially available pumped counterflow virtual impactor (PCVI, model 8100, Brechtel Manufacturing Inc. (BMI), USA; Boulter et al., 2006; Kulkarni et al., 2011) which separates particles based on their inertia. Particles with insufficient inertia to overcome a counterflow are removed, while particles above a certain aerodynamic cut size are transmitted. Further details on characterization of the PCVI transmission efficiency can be found in Sect. 2.6. The ice crystals extracted with the PCVI are subsequently evaporated and the physical and chemical properties of the ice residuals can be probed using on- and offline aerosol instrumentation.

\subsection{Additional instrumentation}

\subsubsection{Small Ice Detector (SID-3)}

The Small Ice Detector (SID-3; Kaye et al., 2008; Ulanowski et al., 2014) which is the aircraft version of the PPD-2K, equivalent in measurement principle and output, was used to measure ice crystal properties during the CLACE 2013 and 2014 campaigns. The SID-3 was mounted on a platform that adjusted itself to the wind direction. An aspiration unit ensured a constant, near isokinietic particle flow through the instrument. The SID-3 directly sampled the unaltered cloud and could thus be used in conjunction with the PPD-2K to assess the impact of the ISI on the ice crystals. The in situ characterization of mixed-phase clouds using the SID-3 is the subject of a publication by Vochezer et al. (2015).

\subsubsection{Ultra-High Sensitivity Aerosol Spectrometer (UHSAS)}

An Ultra-High Sensitivity Aerosol Spectrometer (UHSAS, Droplet Measurement Technologies, Boulder, CO, USA) was deployed during the CLACE 2014 campaign, alternating between sampling downstream of the ISI and downstream of the total inlet. The UHSAS is an optical particle size spectrometer which employs a laser operated at $1054 \mathrm{~nm}$ as the light source. The light scattered by particles is collected over an angle of $22-158^{\circ}$ in the forward direction with the use of two pairs of Mangin mirrors (see Cai et al. (2008) for further details). The UHSAS measures particles in the 60$1000 \mathrm{~nm}$ polystyrene latex (PSL)-equivalent optical diameter size range.

\subsubsection{Wideband Integrated Bioaerosol Sensor (WIBS)}

A Wideband Integrated Bioaerosol Sensor (WIBS, Droplet Measurement Technologies, Boulder, CO, USA) was a further instrument measuring aerosol properties downstream of the ISI and the total inlet. The WIBS instrument employs the UV-LIF method, whereby ultraviolet (UV) light is used to excite the amino-acid tryptophan and nicotinamide adenine dinucleotide (NADH, a molecule involved in cell metabolism), and thus induce fluorescence (Toprak and Schnaiter, 2013). The fluorescence is measured in three channels (fluorescence resulting from excitation by a $280 \mathrm{~nm}$ UV pulse is measured in the $310-400$ and $420-650 \mathrm{~nm}$ wavebands and fluorescence from excitation by a $370 \mathrm{~nm}$ UV pulse in the $420-650 \mathrm{~nm}$ waveband) and allows for detection of biological material. A comparison of the fluorescence properties of ISI ice residuals relative to the total aerosol therefore provides information on the content of bio-material in the ice residuals compared to the bulk aerosol and on its role in initiation of ice formation in the atmosphere.

It should be noted that non-biological fluorescent particles can cause interferences to detection of biological particles. In fact, some types of mineral dust are known to fluoresce. Laboratory studies with different mineral dust types have recently been conducted to assess the cross-sensitivity of bioparticle detection to interferences from mineral dust fluorescence (Toprak and Schnaiter, 2015). Importantly, the signals can be distinguished to a large extent based on the ratios of fluorescence in the three channels, with different signatures obtained from biological material and mineral dust.

\subsection{Omnidirectional inlet and cyclone performance}

In order to establish the performance characteristics of the omnidirectional inlets and the cyclone used during CLACE 2013 and 2014, we have calculated the aspiration efficiency for the conical inlet deployed during CLACE 2013, the transmission efficiency of the modified omnidirectional inlet de- 

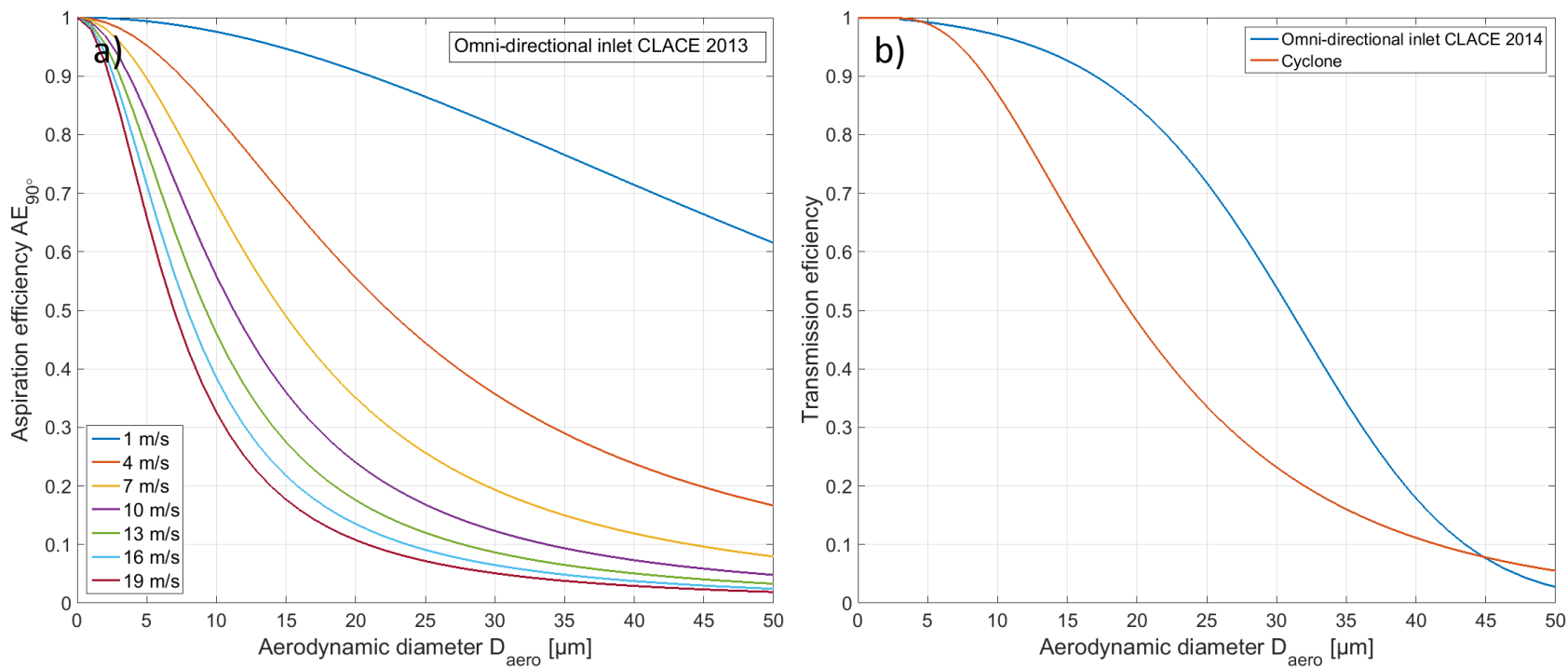

Figure 2. CLACE 2013 omnidirectional inlet (used during CLACE 2013) aspiration efficiency for $90^{\circ}$ sampling (a), CLACE 2014 omnidirectional inlet transmission efficiency (blue curve in panel b) and cyclone (orange curve in panel b) transmission efficiency as a function of aerodynamic diameter $D_{\text {aero }}$ for standard temperature and pressure.

ployed during CLACE 2014, and the transmission efficiency of the BGI cyclone.

The CLACE 2013 omnidirectional inlet aspiration efficiency for $90^{\circ}$ sampling, $A E_{90^{\circ}}$, shown as a function of particle aerodynamic diameter for different wind speeds in Fig. 2a, was calculated based on Eq. (1) following e.g. Mertes et al. (2007), Noone et al. (1992) and Vincent (2007):

$$
A E_{90^{\circ}}=\frac{1}{1+4 G S t R^{0.5}},
$$

where $G$ is a coefficient set to 2.1, St is the Stokes number and $R$ is the ratio of the wind velocity to the inlet velocity. As in Mertes et al. (2007), the maximum inlet diameter $(0.08 \mathrm{~m})$ was used to calculate $S t$, while the minimum diameter $(0.009 \mathrm{~m})$ is used to calculate the inlet velocity, giving $1.83 \mathrm{~m} \mathrm{~s}^{-1}$ for the sampling flow rate of $7 \mathrm{~L} \mathrm{~min}^{-1}$.

During the course of the CLACE 2013 campaign the omnidirectional inlet was found to be prone to clogging by wind-blown snow, and the design of the inlet was subsequently modified prior to the CLACE 2014 campaign. The re-designed inlet, deployed during CLACE 2014, was rainbow-shaped, thus sampling upwards at the open end. Furthermore, a wind shield was added so that aspiration would take place from relatively still air. The transmission efficiency of the CLACE 2014 omnidirectional inlet, assuming sampling from still air, was calculated using the Particle Loss Calculator (von der Weiden et al., 2009) and is shown in Fig. 2b. The transmission efficiency is over $80 \%$ for particles smaller than $20 \mu \mathrm{m}$, and it decreases with increasing particle size to a few percent for particles of $50 \mu \mathrm{m}$ aerodynamic diameter.
The transmission efficiency of the cyclone, shown in Fig. $2 \mathrm{~b}$, has been calculated as follows: firstly, the $D_{50}$ was calculated using Eq. (2), a model fit shown by Kenny and Gussman (1997) to describe the $D_{50}$ for a given cyclone family as a function of the flow rate $Q$ and the cyclone body diameter $D_{c}$ :

$\ln \left(D_{50}\right)=a+b \ln \left(D_{c}\right)-(b-1) \ln (Q)$,

where $a$ and $b$ are empirically derived parameters which depend on the cyclone family and are set here to the values given for the Sharp Cut Cyclone family by Kenny and Gussman (2000). Subsequently, the transmission efficiency is calculated for particle diameters between 0 and $50 \mu \mathrm{m}$ based on the assumption that the collection efficiency can be fitted to a cumulative lognormal distribution function (Wang, 2004). The fraction of particles penetrating the cyclone as a function of particle diameter $P(D)$ is thus calculated as

$P(D)=1-0.5 \operatorname{erf}\left(\frac{\ln (D)-\ln D_{50}}{\sqrt{2} \ln \left(\sigma_{g}\right)}\right)$,

where erf is the error function, $D$ is the particle diameter, $D_{50}$ is the particle diameter for which $50 \%$ of particles are transmitted and $50 \%$ are collected, and $\sigma_{g}$ is the geometric standard deviation of the associated lognormal distribution. $\sigma_{g}$ is equal to the sharpness of the transmission curve, defined as $\left(D_{16} / D_{84}\right)^{0.5}$ (Kenny and Gussman, 2000), and is given by the manufacturer as 1.616 .

The cyclone transmission efficiency is thus $90 \%$ for particles with $D_{\text {aero }}=10 \mu \mathrm{m}, 50 \%$ for particles just under $20 \mu \mathrm{m}$, $20 \%$ for particles with $D_{\text {aero }}=30 \mu \mathrm{m}$ and down to just a few percent for particles with $D_{\text {aero }}=50 \mu \mathrm{m}$. 


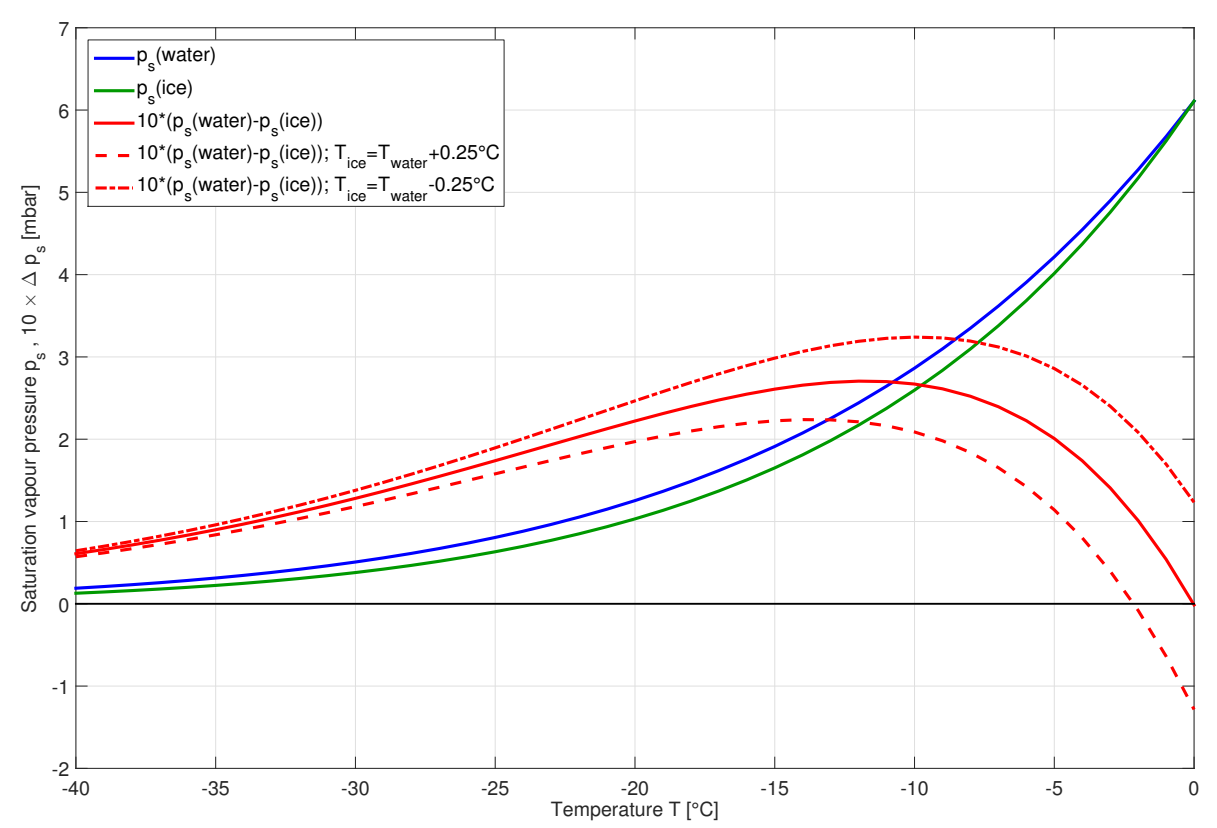

Figure 3. Saturation vapour pressures over bulk liquid water (blue curve) and ice (green curve) surfaces as a function of temperature (the parametrizations used for the saturation vapour pressures over water and ice are based on Lowe and Ficke, 1974). The difference (multiplied by a factor of 10) in the saturation vapour pressures of water and ice is given by the red curve. The difference (multiplied by a factor of 10) in the saturation vapour pressures of water and ice when the ice temperature $\left(T_{\text {ice }}\right)$ is $0.25^{\circ} \mathrm{C}$ higher and lower than the water temperature ( $\left.T_{\text {water }}\right)$ is given by the dashed and dotted red lines respectively.

\subsection{Working principle of the droplet evaporation unit}

The phase separation in the ISI is accomplished with the use of a droplet evaporation unit. The unit used during CLACE 2013 is an anodized aluminium chamber with sandblasted inner walls, a length of $1.5 \mathrm{~m}$ and a volume of $29 \mathrm{~L}$ split in 12 axially symmetrical parts. During operation, the inner walls of the chamber are coated with ice (it should be noted that the temperature of the droplet evaporation unit is not actively controlled; i.e. it follows the ambient air temperature). As a result the air within the chamber is saturated with respect to a flat ice surface, resulting in evaporation of droplets using the Wegener-Bergeron-Findeisen process. This process takes place due to the different saturation vapour pressures over liquid water and ice (Fig. 3; the parametrizations used for the saturation vapour pressures over water and ice are based on Lowe and Ficke, 1974). Consequently, at a given temperature, in an environment saturated with respect to ice (green curve in Fig. 3), there is sub-saturation with respect to water; i.e. the ambient water vapour pressure is below the saturation vapour pressure with respect to water (blue curve in Fig. 3). This difference in saturation vapour pressures over water and ice (red curve in Fig. 3) induces evaporation of the supercooled droplets, while ice crystals are affected to a much lesser degree.

As the temperature of the droplet evaporation unit is not actively controlled, it is possible that there is a slight lag in temperature equilibration of the chamber walls relative to the ambient temperature. In order to monitor whether such a lag takes place, the air temperature inside the evaporation unit and the wall temperature of the chamber were monitored using PT100 (platinum temperature resistance detector) probes. Absolute differences in temperature were on average approximately $0.25^{\circ} \mathrm{C}$. The difference in saturation vapour pressures between water and ice is the driving force for the Wegener-Bergeron-Findeisen process. Therefore, in order to show the influence of the aforementioned temperature lag on this driving force, we show the difference in saturation vapour pressures over water and ice when the ice temperature is $0.25^{\circ} \mathrm{C}$ higher and lower (dashed and dotted red lines respectively in Fig. 3) than the droplet temperature (the droplet temperature is assumed to be equal to the ambient air temperature).

The design of the droplet evaporation unit is based on model calculations solving mass transfer equations and Köhler theory, ensuring sufficient residence time for evaporation of the droplets. The mass transfer equation used follows Seinfeld and Pandis (2006) and gives the growth/evaporation rate of a solution droplet as follows:

$$
D_{p} \frac{\mathrm{d} D_{p}}{\mathrm{~d} t}=\frac{S_{\mathrm{v}, \infty}-S_{\mathrm{eq}}}{\frac{\rho_{\mathrm{w}} R T_{\infty}}{4 p_{\mathrm{s}}\left(T_{\infty}\right) D_{\mathrm{v}}^{\prime} M_{\mathrm{w}}}+\frac{\Delta H_{\mathrm{v}} \rho_{\mathrm{w}}}{4 k_{\mathrm{a}}^{\prime} T_{\infty}}\left(\frac{\Delta H_{\mathrm{v}} M_{\mathrm{w}}}{T_{\infty} R}-1\right)},
$$

where $D_{p}$ is the droplet diameter, $S_{\mathrm{v}, \infty}$ the ambient water vapour saturation ratio, $S_{\text {eq }}$ the equilibrium water vapour saturation ratio of the droplet, $\rho_{\mathrm{w}}$ the density of water, $R$ the 


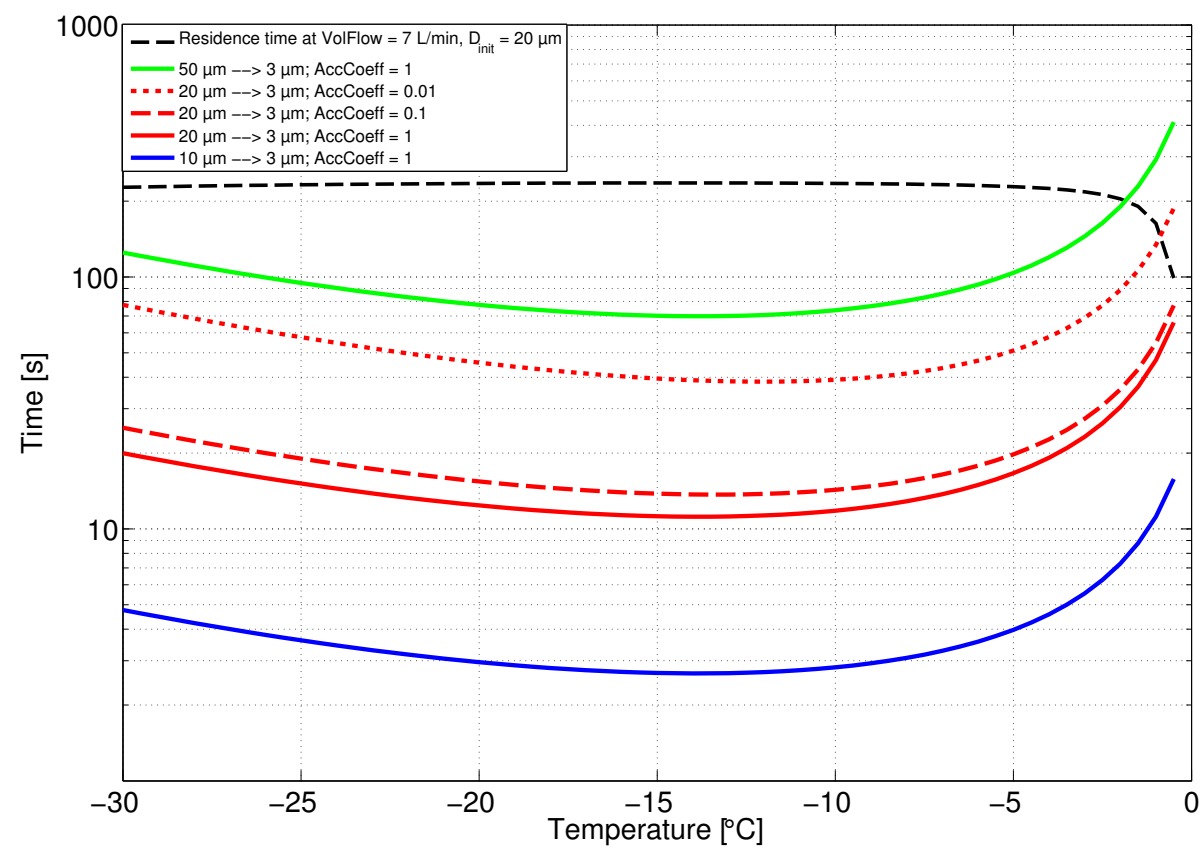

Figure 4. Evaporation times of cloud droplets for different droplet start and end diameters, and different mass accommodation coefficients, as a function of temperature at a pressure of $p=658.61 \mathrm{hPa}$. The average residence time in the CLACE 2013 droplet evaporation unit as a function of temperature based on the dimensions of the droplet evaporation unit and a sample flow of $7 \mathrm{Lmin}^{-1}$ is $\operatorname{shown}$ by the dashed black line.

ideal gas constant, $T_{\infty}$ the ambient temperature, $p_{\mathrm{s}}$ the saturation vapour pressure of water, $D_{\mathrm{v}}^{\prime}$ the water vapour diffusivity corrected for non-continuum effects, $M_{\mathrm{w}}$ the molecular weight of water, $k_{\mathrm{a}}^{\prime}$ the thermal conductivity of air accounting for non-continuum effects and $\Delta H_{\mathrm{v}}$ the latent heat of water evaporation.

Rearrangement and integration of Eq. (4) gives

$\int_{D_{0}}^{D_{1}} \frac{1}{\frac{\rho_{\mathrm{v}, \infty}-S_{\mathrm{eq}}}{\frac{\rho_{\mathrm{w}} R T_{\infty}}{4 p_{\mathrm{s}}\left(T_{\infty}\right) D_{\mathrm{v}}^{\prime} M_{\mathrm{w}}}+\frac{\Delta H_{\mathrm{v}}}{4 k_{\mathrm{a}}^{\prime} T_{\infty}}\left(\frac{\Delta H_{\mathrm{v}} M_{\mathrm{w}}}{T_{\infty} R}-1\right)}} D_{p} \mathrm{~d} D_{p}=\int_{t_{0}}^{t_{1}} \mathrm{~d} t$.

Using the MATLAB R2014a (The Mathworks Inc., USA) software package, Eq. (5) was solved by numeric integration to give the time needed to evaporate a droplet from a set start to a set end diameter, as a function of temperature (Fig. 4). The ambient water vapour saturation ratio was assumed to be at $100 \%$ saturation with respect to a flat ice surface $\left(\mathrm{RH}_{\text {ice }}=100 \%\right)$, the ambient pressure $p$ was set to $658.61 \mathrm{hPa}$ (in order to simulate the ambient conditions at the Jungfraujoch), the equilibrium water vapour saturation ratio of the droplet $S_{\text {eq }}$ was assumed to be 1 (i.e. the Kelvin and Raoult effect are negligible for supermicron-sized cloud droplets) and the mass accommodation coefficient (a component of the $D_{\mathrm{v}}^{\prime}$ term) was set to 1 . A sensitivity analysis of the importance of the mass accommodation coefficient was additionally performed by setting it to 0.1 and 0.01 for the evaporation time calculations of droplets with a set start diameter of $20 \mu \mathrm{m}$. In order to check whether droplet residence times would be sufficient to allow droplet evaporation in the unit, the average residence time as a function of temperature for a $20 \mu \mathrm{m}$ droplet was calculated based on the dimensions of the droplet evaporation unit and a sample flow of $7 \mathrm{~L} \mathrm{~min}^{-1}$. The dashed black line in Fig. 4 shows the average residence time in the evaporation unit.

The calculations of droplet evaporation times based on the aforementioned parameters show that droplets with diameters of $10 \mu \mathrm{m}$ take a few seconds to evaporate to a diameter of $3 \mu \mathrm{m}$, a size well below the cut-off of the PCVI, while $20 \mu \mathrm{m}$ droplets need approximately 10 to $20 \mathrm{~s}$ and $50 \mu \mathrm{m}$ droplets need of the order of $100 \mathrm{~s}$ (Fig. 4). As seen in Fig. 4, there are significant differences in the evaporation rate as a function of temperature. Droplet evaporation takes longest at near-zero temperatures, as well as towards the lower limit of the modelled temperature range, with evaporation times increasing as temperature drops below $-14^{\circ} \mathrm{C}$. The fastest evaporation rates are at a temperature of approximately -12 to $-14{ }^{\circ} \mathrm{C}$. These dependencies can be explained by the difference in saturation vapour pressures over water and ice as a function of temperature (red curve in Fig. 3): the difference is lowest at near-zero and at very low temperatures, and highest between -15 and $-10^{\circ} \mathrm{C}$. Consequently, where the difference and, therefore, driving force for the WegenerBergeron-Findeisen process is highest, evaporation rate is at its fastest, and vice-versa. 


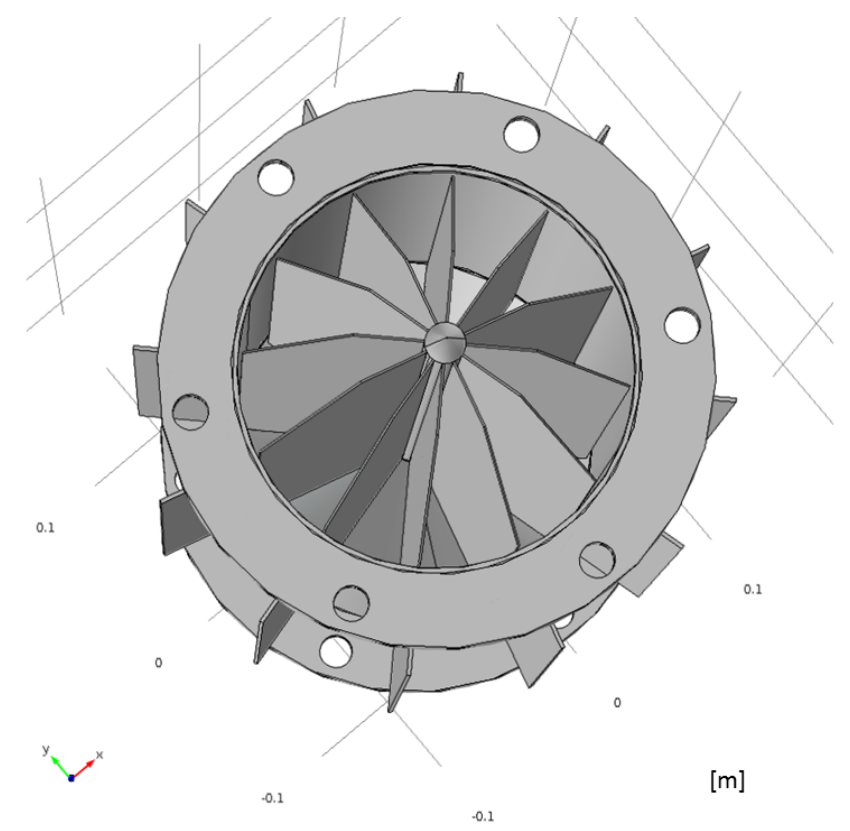

Figure 5. The internal structure of the CLACE 2013 droplet evaporation unit as seen from above.

A potentially important uncertainty in the modelled evaporation times arises due to the uncertainties associated with the assumed mass accommodation coefficient value. Many conflicting studies exist on the value of the mass accommodation coefficient, also called the condensation or evaporation coefficient. Moreover, while some studies assume the condensation and evaporation coefficient to be synonymous (e.g. Fukuta and Walter, 1970; Shaw and Lamb, 1999), other studies highlight that the two coefficients are distinct and can have different values (Eames et al., 1997; Marek and Straub, 2001; Pound, 1972). A review of experimental studies investigating evaporation coefficients conducted by Eames et al. (1997) demonstrates the lack of agreement with wide-ranging values between 0.01 and 1 found in different studies. More recent studies slightly narrow this range to 0.04 and 1 (Laaksonen et al., 2005) (with no differentiation however between the condensation and evaporation coefficients), while aerosol/cloud models have employed values between 0.042 and 1 for the condensation coefficient when modelling droplet growth (Kreidenweis et al., 2003).

While it is outside the scope of this paper to investigate the mass accommodation coefficient of water, we incorporate a simple sensitivity analysis of the mass accommodation coefficient into the modelling study of droplet evaporation rates in order to establish its potential impact on the evaporation rates. The sensitivity analysis is carried out for evaporation of droplets with a set start diameter of $20 \mu \mathrm{m}$ and shows that a decrease in the mass accommodation coefficient by one order of magnitude would result in an increase in the evaporation time of a $20 \mu \mathrm{m}$ droplet by $17-26 \%$. A decrease in the mass accommodation coefficient by two orders of magnitude would result in the droplet evaporation time increasing by $183-288 \%$, depending on the temperature. Meanwhile the residence time of a $20 \mu \mathrm{m}$ droplet in the evaporation unit was calculated to be over $200 \mathrm{~s}$ for temperatures between -2 and $-30^{\circ} \mathrm{C}$. This means that residence time in the droplet evaporation unit should be more than sufficient to ensure evaporation of $20 \mu \mathrm{m}$ droplets. It is important to note that the modelled conditions of $20 \mu \mathrm{m}$ droplet diameter are a worstcase scenario, as droplet sizes are usually significantly below $20 \mu \mathrm{m}$ diameter (e.g. Choularton et al., 2008) and, furthermore, hydrometeors larger than this should be removed by the cyclone.

As regards the geometry of the droplet evaporation unit, an internal structure was designed, as shown in Fig. 5. The internal structure provides a greater inner ice-covered surface, as well as homogenizing the velocity of the sampled air through the droplet evaporation unit (thus slowing down droplet transport and allowing more time for droplet evaporation). Due to the radial construction of the structure, the flow velocity is decreased in the centre of the droplet evaporation unit; the distances between wall surfaces here are smallest resulting in friction between the sample air and chamber walls impacting the air flow velocity to a greater extent than further from the centre of the chamber. As the cone at the centre of the structure forms a surface for potential impaction of hydrometeors, the geometry of the unit was modelled and computational fluid dynamics (CFD) simulations were conducted using the Comsol Multiphysics 4.2a software (Comsol Inc., USA). It should be noted that the geometry used for the CFD modelling is simplified and does not incorporate the internal radial structure, but only the centre cone itself. A visualization of the CFD simulation results, namely a 2-D cross section of the droplet evaporation unit showing the air streamlines and velocity field, is presented in Fig. 6. The Comsol particle tracing module was used in order to model particle transport through the chamber and to establish whether particle losses could be of concern. The simulation was initiated by injecting spherical particles with an aerodynamic diameter of $20 \mu \mathrm{m}$ into the chamber. As in the case of the calculated droplet residence time in the evaporation unit, the simulation was conducted based on the worst-case scenario, with injection of $20 \mu \mathrm{m}$ particles which have a higher stopping distance than smaller particles and are thus more likely to impact on the internal structure, as opposed to following the gas streamlines. The CFD simulations (not shown) of particle trajectories through the droplet evaporation unit showed impaction of large particles to be of minimal importance. Furthermore, the gas flow streamlines simulated show a smooth flow of air through the unit, with only minor eddy formation (which could lead to particle losses if significant) in the upper cone due to an increase in diameter of the sample flow conduit as the flow enters the evaporation tube and is transported through its upper section (Fig. 6). 


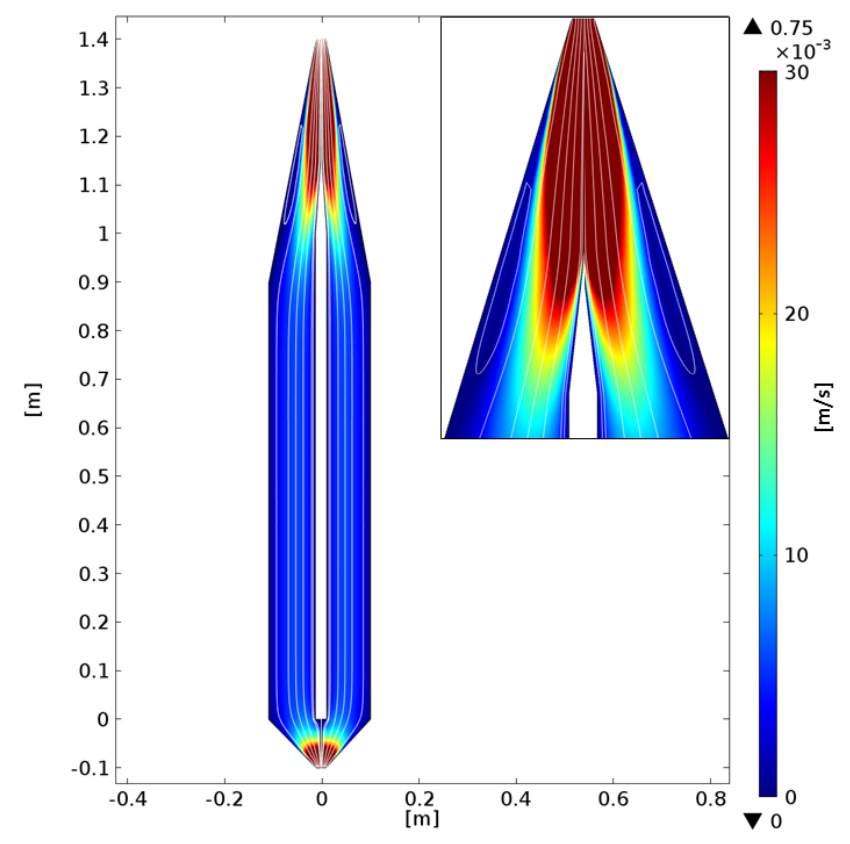

Figure 6. A 2-D cross section of the CLACE 2013 droplet evaporation unit showing the air streamlines and velocity field, calculated using Comsol 4.2a. An enlargement (not to scale) of the upper cone section of the evaporation unit is shown in the inset.

\subsection{WELAS sensor characterization}

The raw signal measured by the WELAS sensors and subsequently converted to a particle number size distribution is a distribution of voltage values representing the scattered light intensities. An empirical factory calibration is used to relate the measured voltage to particle size. The empirical calibration combined with Mie theory provides a relationship in turn between voltage and particle scattering cross section (the latter is directly proportional to the voltage). In order to correct for any drift in instrument sensitivity due to e.g. degradation in the light source or optical fibres, contamination of the optical windows or changes in performance of the photomultiplier, a user calibration is conducted. Hereby particles with a known scattering cross section are aspirated through the measuring volume of the WELAS, with a flow rate of $7 \mathrm{~L} \mathrm{~min}^{-1}$, and the calibration factor is empirically established. CalDust 1100 (provided by the manufacturer), a calibration dust with a refractive index (RI) of 1.43 and a diameter of $1.1 \mu \mathrm{m}$, is used for this purpose. The WELAS sensors are calibrated assuming an RI of 1.59; therefore the calibration factor is adjusted so that the measured size of the monodisperse CalDust is $0.85 \mu \mathrm{m}$ (i.e. the optical diameter of the CalDust particles when assuming they have an RI of 1.59). As the RI of liquid water is 1.33, Mie theory (e.g. Bohren and Huffman, 1998) is subsequently used to correct the measured size distributions for the RI of liquid water. The calculations are conducted with the assumption that the measured parti- cles are spherical. It is important to note that as a result of a single RI being used for the size distribution correction the diameters calculated are incorrect for particles with a different RI, i.e. non-activated aerosol particles and ice crystals. Nonetheless, hydrometeor measurements are the focus of the study, and droplets make up the vast bulk of the hydrometeors measured upstream of the droplet evaporation unit; therefore this approach is deemed satisfactory. A further point to make is that, as ice crystals are highly aspherical, they can only be counted, and not accurately sized, by the WELAS sensors; the shape and orientation of ice crystals in the measuring volume of the WELAS sensor are unknown, and both affect the intensity of scattered light.

The two WELAS 2500 sensors used within the ISI and the respective Promo 2000 control units are, in theory, identical models. Nonetheless, as with all scientific instruments, due to possible slight differences in the machining, assembly and calibration of any two such devices, differences in instrument performance are commonplace. Consequently, we have performed a laboratory characterization of the two WELAS sensors in order to establish the potential error in subsequent comparisons of ambient measurements. The experiment was conducted as follows: the instruments were set up side by side and sampled simultaneously via a common inlet followed by a Y-splitter. A3 medium-grade Arizona Test Dust (ISO 12103-1; Powder Technology Inc, USA) was used as the test aerosol. The aerosol was dispersed using a vial shaker (Edmund Bühler GmbH, Germany). The WELAS sensors measured the number size distribution of the sampled aerosol in the PSL-equivalent size range of approximately $0.6-40 \mu \mathrm{m}$. Using Mie theory, the measured size distribution was corrected for particles with the refractive index of Arizona Test Dust (the RI across the WELAS effective light spectrum is assumed to have real and imaginary parts of $n=1.51$ and $k=0.0012$ respectively, as given by Glen and Brooks, 2013).

The size distributions measured during the instrument characterization are presented in Fig. 7, together with the ratio of the total number of counts per size bin measured by the two sensors (red line in Fig. 7). The ratio shows that there are considerable differences in the relative counting efficiencies of the two sensors at the smallest sizes, with the ratio of WELAS 2 to WELAS 1 counts steadily increasing from $20 \%$ to just under $100 \%$ for 0.5 to $1 \mu \mathrm{m}$ particles. The relative counting efficiency is in fairly good agreement for particles between 0.8 and $11 \mu \mathrm{m}$, albeit with WELAS 2 predominantly under-counting by $10-20 \%$ as compared to WELAS 1. Above $11 \mu \mathrm{m}$ the ratio of counts increases considerably in the experiment shown.

The $S$ shape of the ratio of WELAS 2 to WELAS 1 counts could be explained by a difference or an inherent uncertainty in the CalDust user calibration. An over-amplification of the signal for WELAS 2 (or an under-amplification for WELAS 1) would result in a relative shift in the measured size distribution of WELAS 2 towards larger sizes, thus re- 


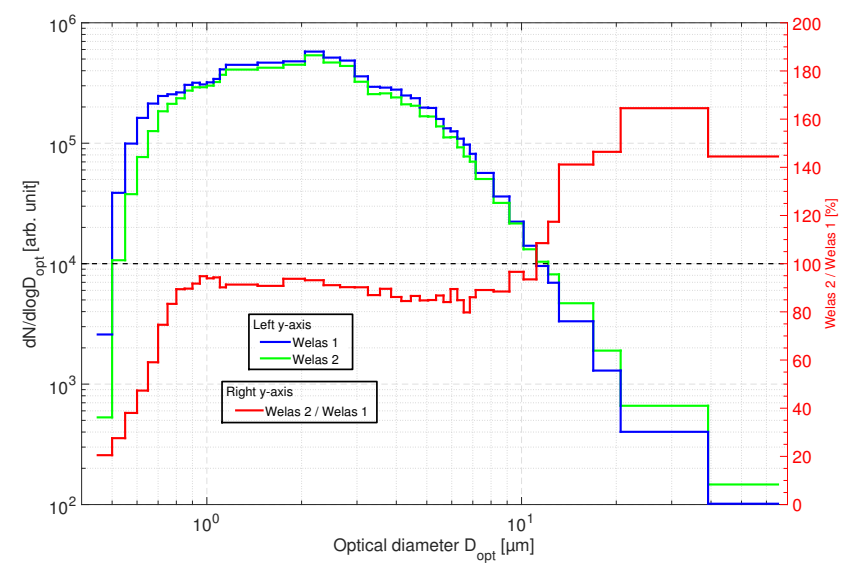

Figure 7. Intercomparison of the ISI WELAS optical particle size spectrometers.

sulting in under-counting of WELAS 2 with respect to WELAS 1 where the gradient of the size distribution is positive and over-counting where the gradient is negative (as observed during the experiment). Additionally, the larger differences in counting efficiencies measured at smaller sizes can be explained by the fact that at these sizes there is relatively little scattered light reaching the WELAS detector. As a result, any differences in construction or calibration of the sensors will have an increasingly strong influence on particles as their size decreases towards the lower detection limit of the WELAS sensors. This could be considered an issue for some measurement purposes; however, as we are interested in supermicron-sized hydrometeors, it does not pose a major problem for measurements of droplets and ice crystals in the ISI. Nonetheless the inter-comparison shows that a systematic error of up to approximately $20 \%$ should be recognized when discussing further results of the WELAS measurements.

\subsection{PCVI characterization}

A defining characteristic of an impactor device is its sizedependent transmission efficiency (TE), particularly the $D_{50}$. Characterization of the PCVI transmission efficiency has been performed in several previous studies (Boulter et al., 2006; Kulkarni et al., 2011). As a result, we have focused solely on validating the characterization for those flow settings that were deemed relevant to our inlet setup.

The characterization performed within the scope of this study was carried out via dispersion of ATD as the test aerosol, as opposed to the nebulization of salt solutions used in previous studies. In order to establish the size-dependent $\mathrm{TE}$, the following laboratory experiment was conducted (see Fig. 8 for a schematic of the laboratory setup): Arizona Test Dust was dispersed with the use of the Topas Solid Aerosol Generator (SAG 410; Topas GmbH, Germany). In order to smooth concentration fluctuations due to changes in the out-

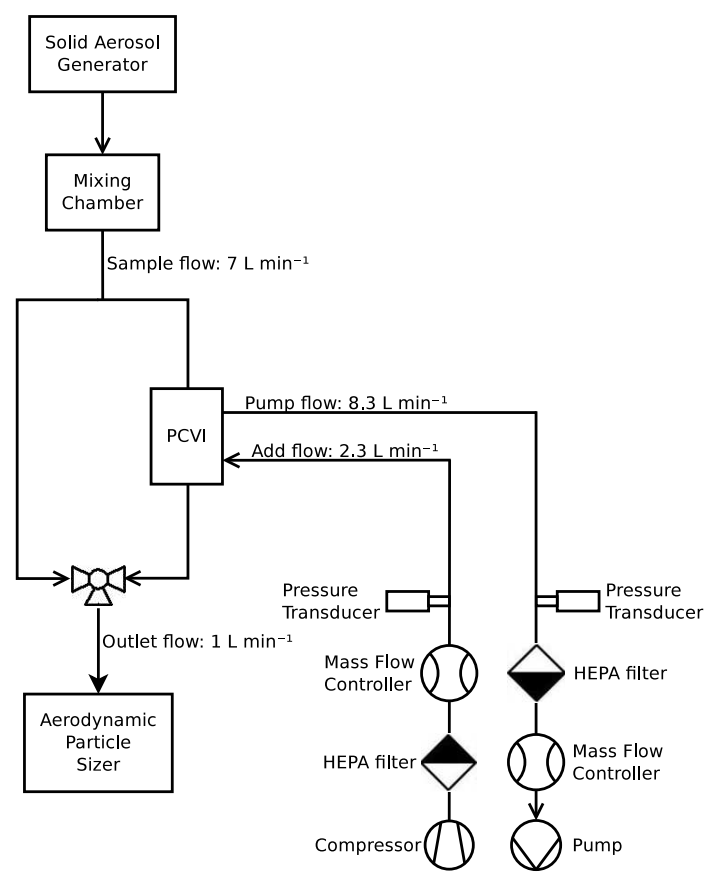

Figure 8. Schematic of the laboratory setup for the pumped counterflow virtual impactor (PCVI) transmission efficiency tests.

put rate of the SAG, the flow was passed through a mixing chamber before being sent either through the PCVI or through a bypass. A three-way valve was used to switch between PCVI and bypass in alternating cycles of $30 \mathrm{~s}$ duration. The PCVI flow settings used during the characterization were identical to those used subsequently during the CLACE 2013 and CLACE 2014 field campaigns (sample flow: $7 \mathrm{~L} \mathrm{~min}^{-1}$ ; pump flow: $8.3 \mathrm{~L} \mathrm{~min}^{-1}$; add flow: $2.3 \mathrm{~L} \mathrm{~min}^{-1}$; and outlet flow: $1 \mathrm{~L} \mathrm{~min}^{-1}$ ). Number size distributions were measured downstream of the PCVI and downstream of the bypass by the TSI Aerodynamic Particle Sizer (APS) model 3321 in the size range of $0.5-20 \mu \mathrm{m}$ aerodynamic diameter. The number size distribution measured downstream of the PCVI was corrected for enrichment in the PCVI, which is approximately equal to the ratio of the inlet and outlet flow (Boulter et al., 2006). The transmission efficiency of the PCVI was subsequently obtained by taking the ratio of the corrected number size distribution downstream of the PCVI to that measured downstream of the bypass.

The result of one such experiment is presented in Fig. 9. As is immediately clear, there is very little transmission of particles in the size range of $0.5-2 \mu \mathrm{m}$ through the PCVI $(<0.05 \%)$. As noted above, the lower detection limit of the APS is $0.5 \mu \mathrm{m}$; therefore no measurements are available for particles $<0.5 \mu \mathrm{m}$. However, as smaller particles have increasingly lower inertia, it can safely be assumed that the sub-0.5 $\mu \mathrm{m}$ transmission is similar to or lower than that of the smallest particles measured by the APS. Transmission efficiency increases sharply for particles above $3.5 \mu \mathrm{m}$ in aerody- 


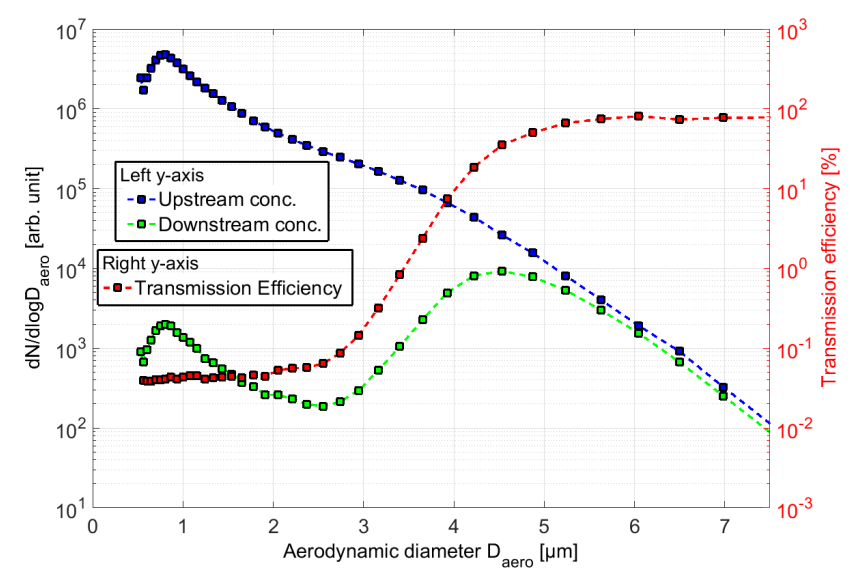

Figure 9. Transmission efficiency of the BMI PCVI, with flows of $7 \mathrm{~L} \mathrm{~min}^{-1}$ (sample flow), 8.3 $\mathrm{L} \mathrm{min}^{-1}$ (pump flow), $2.3 \mathrm{~L} \mathrm{~min}^{-1}$ (add flow) and $1 \mathrm{~L} \mathrm{~min}^{-1}$ (outlet flow), as measured by a TSI model 3321 Aerodynamic Particle Sizer.

namic diameter, with a $D_{50}$ of $4.9 \mu \mathrm{m}$, and the plateau value with a maximum TE of about $80 \%$ is reached for particles larger than approximately $6 \mu \mathrm{m}$. The few smaller particles transmitted likely originate from one of the potential measurement artefacts described by Pekour and Cziczo (2011), i.e. capture in the wake of larger particles, collision and coalescence with larger particles, and subsequent detrainment in the output flow, or collision with larger particles imparting sufficient kinetic energy to the smaller particle for it to cross the stagnation planes. Furthermore, it should be noted that due to these artefacts the transmission of particles smaller than the PCVI cut size is dependent on the number concentrations of both small and large particles and thus changes to some extent from case to case.

The measured transmission pattern is in line with the idealized TE curves derived from CFD simulations in Kulkarni et al. (2011), to which the reader is referred for an in-depth discussion of the curve morphology. The maximum TE observed is also similar to that reported by both Boulter et al. (2006) and Kulkarni et al. (2011), with an imperfect TE being attributed to losses on the internal fittings of the PCVI. However, the $D_{50}$ measured was consistently higher than that measured for very similar flow settings by Kulkarni et al. (2011) (case number 5), with a $D_{50}$ of $4.9 \mu \mathrm{m}$ in our characterization, as compared to $3.21 \mu \mathrm{m}$ in Kulkarni et al. (2011). As it is of the utmost importance to remove all interstitial particles from the sample flow, the higher cut-off size is not detrimental for our purposes, and based on our laboratory characterization the performance of the PCVI was deemed adequate.

The experiments described above were conducted at an ambient pressure of 960 mbar. Meanwhile, ambient pressure at the Jungfraujoch is $650 \mathrm{mbar}$. This raises the question of whether the transmission efficiency of the PCVI is pressure dependent. A comparison of the transmission efficiency of the PCVI at ambient pressures of 1000 and $600 \mathrm{mbar}$ has been conducted by L. Schenk (Leibniz Institute for Tropospheric Research, Leipzig, Germany, personal communications) using a pressure-controlled vessel as the sample volume and a PCVI model identical to the one used in this study (BMI, model 8100). Good agreement of the transmission efficiency for set sample volume pressures of 600 and $1000 \mathrm{mbar}$ was found, with the transmission efficiency curves similar in shape, albeit with a small shift of the $D_{50}$ aerodynamic diameter by 0.5 from $4.6 \mu \mathrm{m}$ at an ambient pressure of $1000 \mathrm{mbar}$ to $5.1 \mu \mathrm{m}$ at an ambient pressure of 600 mbar. Consequently, it is concluded that the transmission efficiency of the PCVI is not strongly affected by the lower ambient pressure at the Jungfraujoch.

\section{ISI field measurements: deployment at the Jungfraujoch}

First deployment of the ISI in the field was carried out as part of an international field campaign: CLACE 2013 in January-February 2013. A second campaign, with a modified ISI setup (re-designed omnidirectional inlet and droplet evaporation tube), was conducted in January-February 2014 (CLACE 2014). The campaigns were conducted at the highaltitude research station Jungfraujoch (3580 ma.s.1.) in the Swiss Alps. As part of the CLACE 2013 campaign, three aerosol inlets were operated (total aerosol inlet (Weingartner et al., 1999), Ice-CVI (Mertes et al., 2007) and ISI (this paper)), as well as ice nuclei counters and a host of cloud microphysical probes deployed by collaborators from Germany, the UK and Switzerland. A similar setup, albeit with reduced instrumentation, was used during CLACE 2014. In particular, only the total aerosol inlet and the ISI were deployed during CLACE 2014. The comprehensive set of measurements involved physical and chemical characterization of the total aerosol, ice residuals and ice nuclei, as well as hydrometeor concentration and size distribution measurements and measurements of ice crystal properties, such as shape, habit and surface roughness.

In the following, a comparison of SID-3 and ISI WELAS cloud microphysical measurements is presented (Sect. 3.1). Subsequently, measurements of hydrometeors based on the optical particle spectrometers within the ISI are discussed (Sect. 3.2), with focus on validating the working principle of the droplet evaporation unit. A comparison of average incloud WELAS size distributions and PPD-2K number concentrations for CLACE 2013 and CLACE 2014 is presented in Sect. 3.3, demonstrating the increase in transmission of ice crystals following the modification of the droplet evaporation unit post-CLACE 2013. Selected ice residual measurements conducted with an UHSAS during CLACE 2014 are presented in Sect. 3.4, demonstrating the capability of the ISI to extract ice residuals. Finally, measurements of fluorescent particles during a Saharan dust event are discussed in 


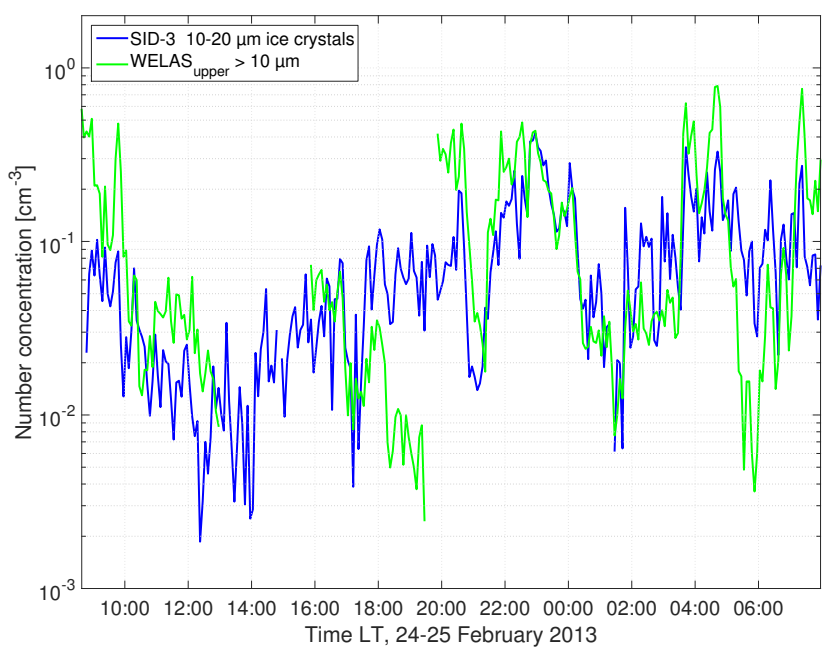

Figure 10. Comparison of the number concentrations of cloud particles $>10 \mu \mathrm{m}$ optical diameter $D_{\text {opt }}$ measured by the upper WELAS (green line) and ice crystals with optical diameters $D_{\text {opt }}$ of $10-20 \mu \mathrm{m}$ (blue line) measured by the SID-3 on 24-25 February 2013.

Sect. 3.5, showing the first indication of enrichment of biomaterial in sub- $2 \mu \mathrm{m}$ ice residuals.

\subsection{Sampling efficiency of the ISI down to the upper WELAS}

In order to verify the sampling efficiency of ice crystals by the ISI, we compare the number concentration of particles larger than $10 \mu \mathrm{m}$ measured by the upper WELAS with the number concentration of small ice particles detected by the SID-3 probe (Fig. 10). The SID-3 instrument was the only cloud probe operated during the CLACE 2013 and 2014 campaigns able to distinguish between liquid droplets and ice crystals in the size range probed by the ISI, i.e. 5-20 $\mu \mathrm{m}$. However, in order to maximize the number of ice crystal scattering patterns acquired, the SID-3 camera exposure trigger threshold during CLACE 2013 was set to a level above that of the signal generated by liquid droplets and small $(5-20 \mu \mathrm{m})$ ice crystals; otherwise the camera is predominantly occupied with acquisition of scattering patterns of the much more numerous droplets, which are of limited interest. Nonetheless, on several occasions the trigger threshold was decreased to ensure small ice crystals were also imaged. One such occasion was 24-25 February 2013, with simultaneous ISI upper WELAS and SID-3 measurements with a lowered trigger threshold, thus providing a valuable opportunity for an inter-comparison (shown in Fig. 10 for the period 08:45 LT (local time) on 24 February 2013 to 08:00 LT on 25 February 2013). For the inter-comparison of number concentrations a lower size threshold of $10 \mu \mathrm{m}$ optical diameter is used for cloud particles measured by the upper WELAS sensor in the ISI, thus ensuring the particles counted are predominantly ice crystals, while the droplets, which are smaller, are excluded. Correspondingly, for the SID-3 we show the number concentration of ice crystals measured in the 10-20 $\mu \mathrm{m}$ size range.

As seen in Fig. 10 the measured upper WELAS $>10 \mu \mathrm{m}$ cloud particle and SID-3 ice crystal number concentrations are on the same order of magnitude, albeit sometimes with several factors' difference between the SID-3 and upper WELAS concentrations. At times, partial or complete clogging of the ISI by wind-blown snow resulted in a decrease in the measured WELAS concentrations, as observed, for example, at approximately 18:00 LT on 24 February. After cleaning of the inlet, the measured concentrations increased. Furthermore, the difference in the magnitude of measured WELAS and SID-3 concentrations might partially be due to the fact that the sizing of particles in the two instruments is based on the particle scattering signal recorded under different angles and is thus not fully comparable. Most importantly, however, the trends of the measured number concentrations are in reasonably good agreement. This is strong evidence that the ISI is successfully sampling small ice crystals from the ambient environment.

\subsection{ISI WELAS hydrometeor measurements}

A comparison of size distributions measured by the two WELAS sensors upstream and downstream of the droplet evaporation unit during a mixed-phase cloud measurement (19:55 LT on 12 February 2013 to 01:20 LT on 13 February 2013) is shown in Fig. 11, highlighting the strengths and weaknesses of the ISI.

Air temperature during the case study period was in the range of -20 to $-22^{\circ} \mathrm{C}$ (black curve in Fig. 11a), dropping gradually during this period. Liquid water content (LWC), measured by a particulate volume monitor (PVM-100, Gerber Scientific Inc., USA), fluctuated between approximately 0.1 and $0.5 \mathrm{~g} \mathrm{~m}^{-3}$ (blue curve in Fig. 11a). It should be noted that, as the PVM-100 signal responds also to ice crystals (Verheggen et al., 2007), the LWC measurements cannot be considered as absolute values in the presence of ice. The upper WELAS size distributions (see Fig. 11b and d) show high concentrations of hydrometeors with a mode between approximately 2 and $14 \mu \mathrm{m}$. These are assumed to be predominantly supercooled droplets based on a comparison with the scattering patterns recorded by the SID-3 (not shown). The SID-3 measurements confirm also the presence of ice in the cloud. The case study period was therefore a prolonged period of time during which the ISI sampled in mixed-phase cloud conditions.

Fig. $11 \mathrm{~b}$ and c present the contour plots of the $60 \mathrm{~s}$ timeresolved size distributions during the case study period as measured by the WELAS sensors up- and downstream of the droplet evaporation unit respectively. Figure 11d shows the case study average concentration per size bin for each sensor, along with a description of the processes occurring within the ISI and their effect on the measured size distributions. It 

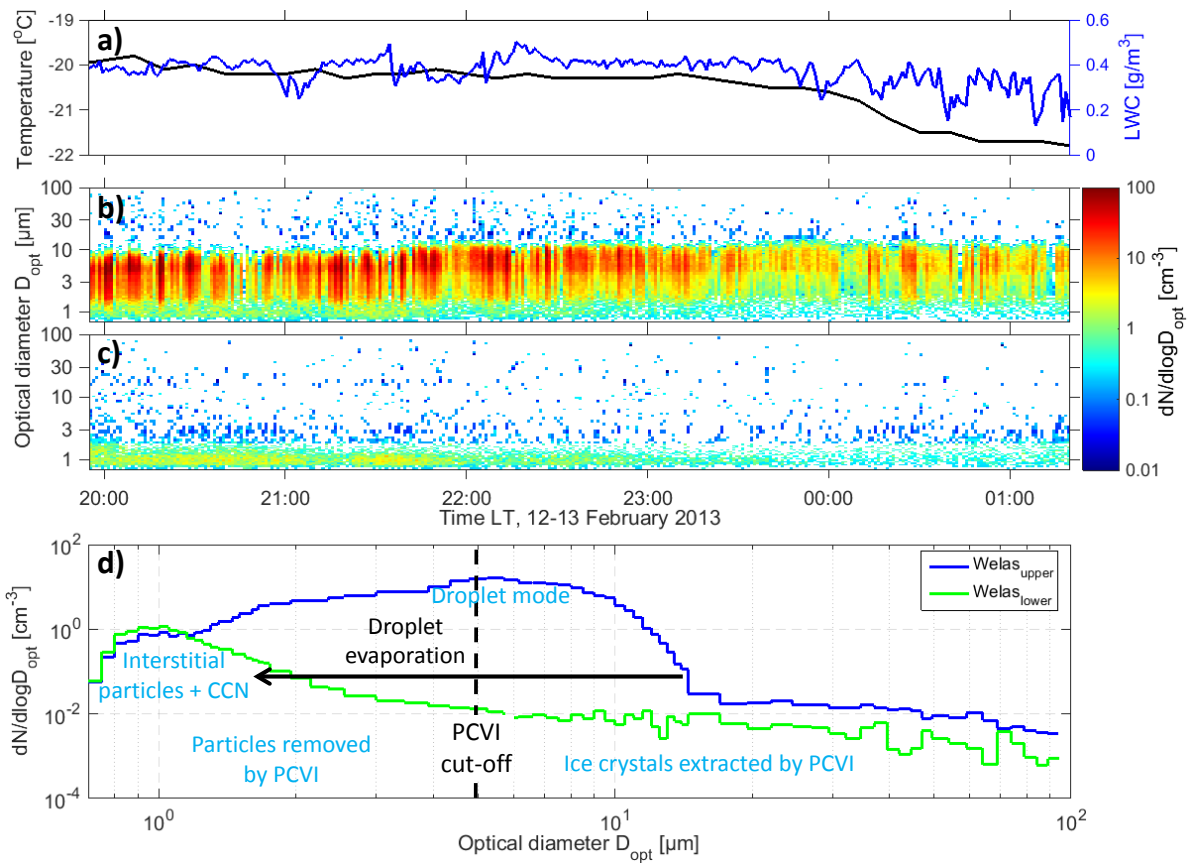

Figure 11. Measurements of liquid water content, air temperature and particle number size distributions during the CLACE 2013 case study period of 19:55 LT, 12 February 2013 to 01:20 LT, 13 February 2013. Panel (a) shows air temperature (black curve) and liquid water content (blue curve); panels (b) and (c) show time resolved size distributions measured with the upper and lower ISI WELAS 2500 sensors respectively; and panel (d) shows average size distributions for the case study period from the two WELAS sensors with an overlaid description of the processes at work in the ISI, and the resulting size distribution characteristics.

is important to note that the presented size distributions assume an RI of 1.33 for all measured particles. As mentioned in Sect. 2.5 this means that, while droplets are sized correctly, non-activated aerosol particles, which typically have a much higher RI, appear at much larger sizes than their true geometric diameter.

The comparison of WELAS size distributions suggests that droplets are removed very efficiently by the evaporation unit: the droplet mode clearly visible during the MPC event in the upper WELAS size distribution is removed by the ISI, as seen in the lower WELAS size distribution. The removal of droplets is confirmed by the PPD-2K measurements, which shows that the remaining hydrometeors are almost exclusively ice crystals. In the time frame selected for the case study the PPD- $2 \mathrm{~K}$ recorded 1248 scattering patterns, from which 10 were classified as droplets. This corresponds to a fractional droplet interference downstream of the droplet evaporation unit of $0.8 \%$. The classification was based on the variance of the azimuthal intensity of the patterns (the classification method is described in detail by Vochezer et al., 2015) and a manual cross-check. The finding that the PPD$2 \mathrm{~K}$ recorded mainly ice particles was confirmed in various cases throughout the campaign and leads to the conclusion that the dominating hydrometeors transmitted by the ISI are ice particles.
As seen in Fig. 11d, the transmitted fraction of larger particles above approximately $14 \mu \mathrm{m}$ is much higher than of particles in the sub-14 $\mu \mathrm{m}$ range, where the droplet mode is present. Due to the rapid growth of ice crystals in the presence of supercooled liquid droplets in mixed-phase clouds, these larger particles are expected to be predominantly ice crystals. Although the transmitted fraction of larger particles is much higher, there are significant losses of these particles in the droplet evaporation unit.

A remark to be made with regards to the presented size distributions is that ice crystals are measured even at sizes up to $100 \mu \mathrm{m}$. Meanwhile, as shown in Fig. 2, both the omnidirectional inlet and the cyclone have very low transmission efficiencies for such large particles. This feature can be explained by the fact that the scattering phase functions of ice crystals and water droplets differ considerably. For example, as shown in Fig. 3 of McFarlane and Marchand (2008), for an effective radius of $25 \mu \mathrm{m}$, ice crystals scatter approximately an order of magnitude more (depending on their habit) than water droplets at an angle of $90^{\circ}$. As the WELAS measure light scattered at an angle of $90 \pm 12^{\circ}$ by particles passing through the sensing volume, the ice crystals are greatly oversized by the instrument.

The PPD-2K provides important clues with regards to the process behind the imperfect transmission of the ice crystals. Figure $12 \mathrm{~b}$ and $\mathrm{c}$ display the ice crystal scattering pat- 


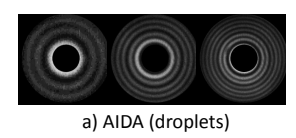

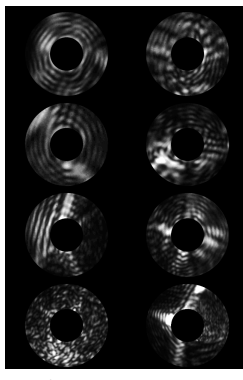

b) SID-3: CLACE 2013

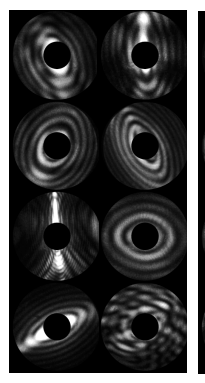

c) PPD-2K: CLACE 2013

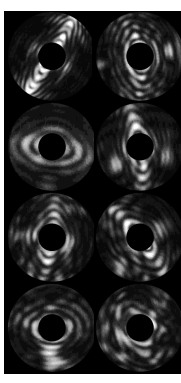

d) AIDA

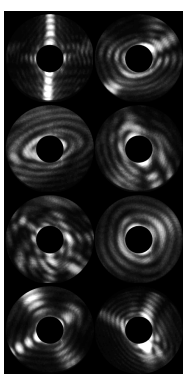

e) PPD-2K: CLACE 2014
Figure 12. Randomly selected droplet scattering patterns recorded by the PPD-2K at the AIDA cloud chamber (RICE01 campaign, experiment 09) (a) and randomly selected ice crystal scattering patterns recorded by the SID-3 directly sampling ambient air during CLACE 2013 between 18:20 and 18:30 LT on 12 February 2013 (b); by the PPD-2K downstream of the ISI during CLACE 2013 between 19:55 LT on 12 February 2013 and 01:20 LT on 13 February 2013 (c); by the PPD-2K directly connected to the AIDA cloud chamber during the final stage of an ice cloud experiment (RICE02 campaign, experiment 18) (d); and by the PPD-2K downstream of the ISI during CLACE 2014 between 09:20 and 11:00 LT on 14 February 2014 (e). The patterns display the distribution of scattered light measured between 0 and $26^{\circ}$ relative to the forward direction. The black area in the centre of the SID-3 and PPD-2K scattering patterns is due to the beam dump of the SID-3 and PPD-2K.

terns recorded during CLACE 2013 by the SID-3 (directly sampling ambient air) and by the PPD-2K (downstream of the ISI) respectively, while Fig. 12a shows droplet scattering patterns from an experiment at the Aerosol Interactions and Dynamics in the Atmosphere (AIDA) cloud chamber (e.g. Möhler et al., 2005), shown for comparison purposes (see Kaye et al. (2008) and Vochezer et al. (2015) for details on differentiating between spherical droplets and ice crystals). SID-3 records indicate a dominant presence of liquid droplets during the case study period, indicating that a MPC was present (note: only ice crystal scattering patterns are shown in Fig. 12b). Due to the SID-3 camera trigger settings used during the case study period, SID-3 data on small ice particles are available only $1.5 \mathrm{~h}$ prior to the time period of the presented case study. The meteorological conditions however stayed rather constant, and the SID-3 scattering patterns displayed in Fig. 12b are typical for the SID-3 measurements of small ice crystals during CLACE 2013.

Comparing the general features of the scattering patterns displayed in Fig. $12 \mathrm{~b}$ and $\mathrm{c}$, one notes that the patterns recorded by the PPD-2K downstream of the ISI (Fig. 12c) show a more rounded structure than those measured by the SID-3 directly sampling the ambient air (Fig. 12b). This indicates that the ice particles are altered during their passage through the ISI evaporation unit. In order to explain this dis- crepancy, the scattering patterns observed by the PPD-2K during the case study period (Fig. 12c) have been compared to those collected by the same instrument during a cloud chamber experiment: in Fig. 12d patterns are displayed that were recorded at the AIDA cloud chamber within an ice cloud experiment during sublimation of ice particles. Patterns in Fig. 12c and d show similar rounded features. Applying diffraction theory as a first approximation to interpret the scattering patterns, we expect rounded patterns to be correlated to rounded ice particles. Thus the patterns displayed in panels (c) and (d) both suggest the presence of rounded ice particles. Together with the disappearance of particles indicated by the low transmission efficiency in Fig. 11, we suspect the ice particles have been sublimated during their passage through the ISI evaporation chamber. Rounding of ice particles as an indicator of ice crystal sublimation was also found by Heymsfield and Iaquinta (2000), Nelson (1998), and Sassen et al. (1994). Similar scattering patterns were recorded by the PPD-2K throughout the CLACE 2013 campaign in general, and the case study period in specific (Fig. 12c), pointing to sublimation of ice crystals as the cause for their imperfect transmission. There are a number of possible reasons for the sublimation, which we hypothesize on as follows: firstly, if the chamber walls are colder than the cloud, the relatively warmer cloud ice crystals sublimate in the presence of the colder chamber wall. Secondly, if the chamber walls are warmer than the ambient air temperature, the ice cover in the evaporation chamber becomes patchy, i.e. parts of the wall surface would become ice-free. This transient effect would potentially lead to ice crystal growth in the short-term. However, once the walls become partially ice-free, the air entering the evaporation chamber becomes sub-saturated with respect to ice in the vicinity of the ice-free wall surfaces (due to the warming influence of the chamber walls on the incoming air) and ice particle sublimation occurs. Thirdly, the higher saturation vapour pressure over the relatively more curved surfaces of the ice crystal as compared to the flat ice walls of the evaporation chamber (a phenomenon equivalent to the Kelvin effect for liquid droplets) could lead to ice crystal sublimation. Finally, as different facets, edges and structures of the ice crystal surface have different saturation vapour pressures, reshaping of the crystal takes place. Studies on the dynamics of ice crystal growth and sublimation using scanning electron microscopy conducted by Pfalzgraff et al. (2010) hint at such a process; however temperature and pressure conditions differ significantly from those experienced at the Jungfraujoch. An important note to make in the context of ice crystal reshaping is that ice particle shape is not expected to be stable even in an ice-saturated environment (as deposition and sublimation still occur in equilibrium). This constitutes a major obstacle for investigating ice microphysical properties such as habit and surface roughness with a sampling system like the ISI in mixed-phase cloud conditions. In order to address this issue, a smaller droplet evaporation 

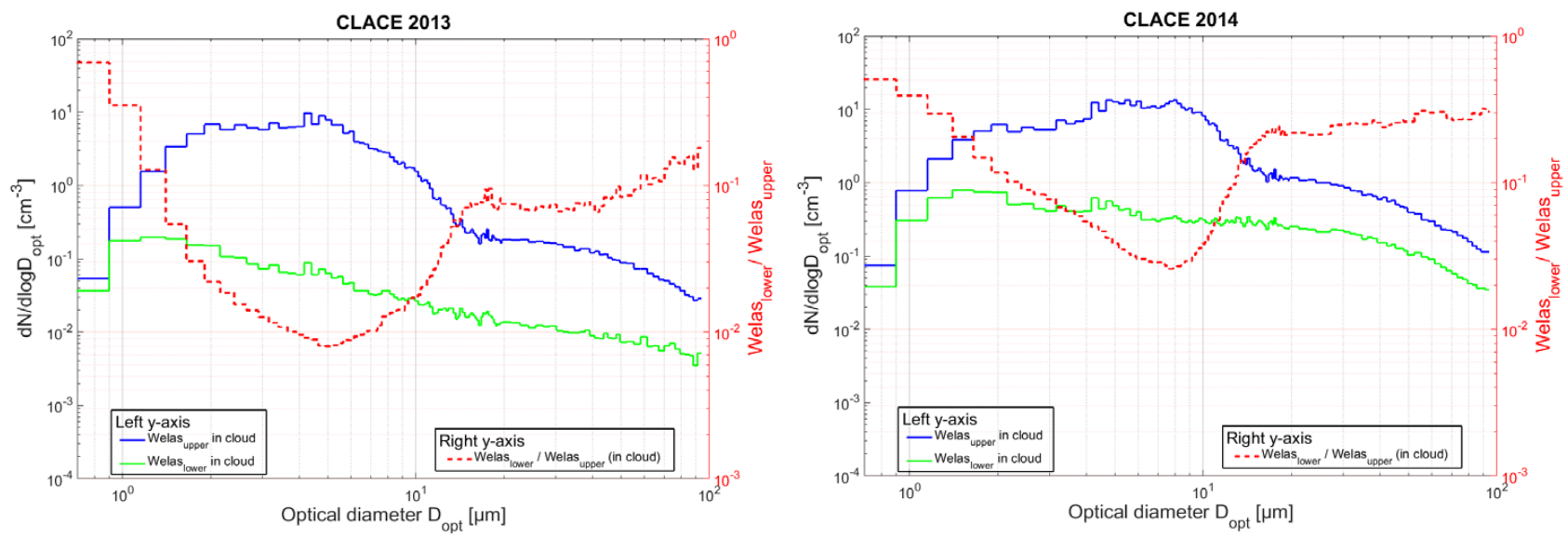

Figure 13. Averaged WELAS size distributions measured in cloud during CLACE 2013 (left panel) and CLACE 2014 (right panel) upstream and downstream of the droplet evaporation unit. The upper WELAS size distribution is given by the blue line, lower WELAS size distribution by the green line and the ratio of lower WELAS to upper WELAS size distributions by the dashed red line.

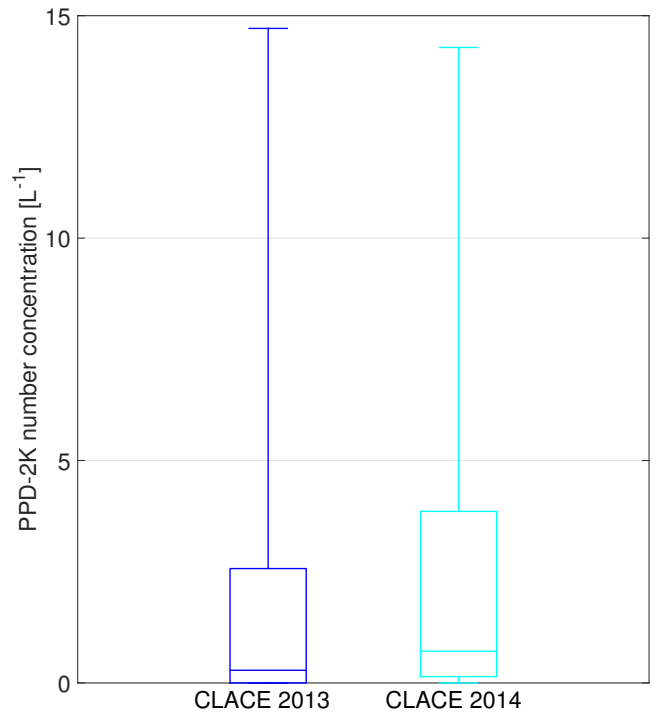

Figure 14. PPD-2K measurements from the ISI during CLACE 2013 and 2014. The box plot gives the median (line in the box), 25th and 75 th percentile (box edges), and the 10th and 90th percentiles (whiskers) of the $1 \mathrm{~min}$ PPD-2K total concentration measurements in cloud during the two campaigns.

tube was used (length of $0.6 \mathrm{~m}$ and volume of $4.7 \mathrm{~L}$ ) during CLACE 2014. Panel (e) of Fig. 12 shows PPD-2K patterns recorded during CLACE 2014. In general the PPD-2K patterns show less-rounded features. A detailed comparison of the performance of the two different droplet evaporation tube designs and a discussion of the effect on ice crystal structure are found in Sect. 3.3.

\subsection{Cloud particle transmission through the droplet evaporation unit}

In order to quantify the losses of ice crystals in the droplet evaporation tube, and the impact of modifying the droplet evaporation tube following the CLACE 2013 campaign, we have calculated averaged in-cloud size distributions for particles measured upstream and downstream of the droplet evaporation tube during the CLACE 2013 and 2014 campaigns. The size distributions (Fig. 13) show similar general features to the case study size distributions described in Sect. 3.2, with the droplet mode clearly visible in the upper WELAS and removed in the lower WELAS. The transmission efficiency of particles through the droplet evaporation unit can be quantified by taking the ratio of the lower to upper WELAS size distributions (red line in Fig. 13). During CLACE 2013 the low transmission efficiency coinciding with the size range of the droplet mode increases as the droplet mode counts begin to decrease (and the ratio of ice crystals to droplets increases) at an optical diameter of $D_{\mathrm{opt}}=5 \mu \mathrm{m}$, reaching a level of approximately $7-18 \%$ for particles with $D_{\text {opt }}$ larger than $15 \mu \mathrm{m}$, i.e. particles that are assumed to be almost solely ice crystals. The ratio for CLACE 2014 shows a similar pattern; however the increase in transmission efficiency takes place at a size of $D_{\mathrm{opt}}=8 \mu \mathrm{m}$, and the ratio goes up to approximately $20-32 \%$ for particles with $D_{\text {opt }}$ larger than $15 \mu \mathrm{m}$. The increase in transmission efficiency is attributed to the redesigned droplet evaporation tube used during CLACE 2014 with much lower residence times $(30 \mathrm{~s})$ than the CLACE 2013 model ( $230 \mathrm{~s})$, thus resulting in a decrease in the sublimation of ice crystals. Cloud particle measurements from the PPD-2K also show an increase in the number of particles transmitted through the inlet. A box plot of CLACE 2013 and CLACE 2014 PPD-2K measurements (Fig. 14) shows an increase in the campaign median number concentration measured from 0.29 to $0.71 \mathrm{~L}^{-1}$, while the 25 th percentile in- 

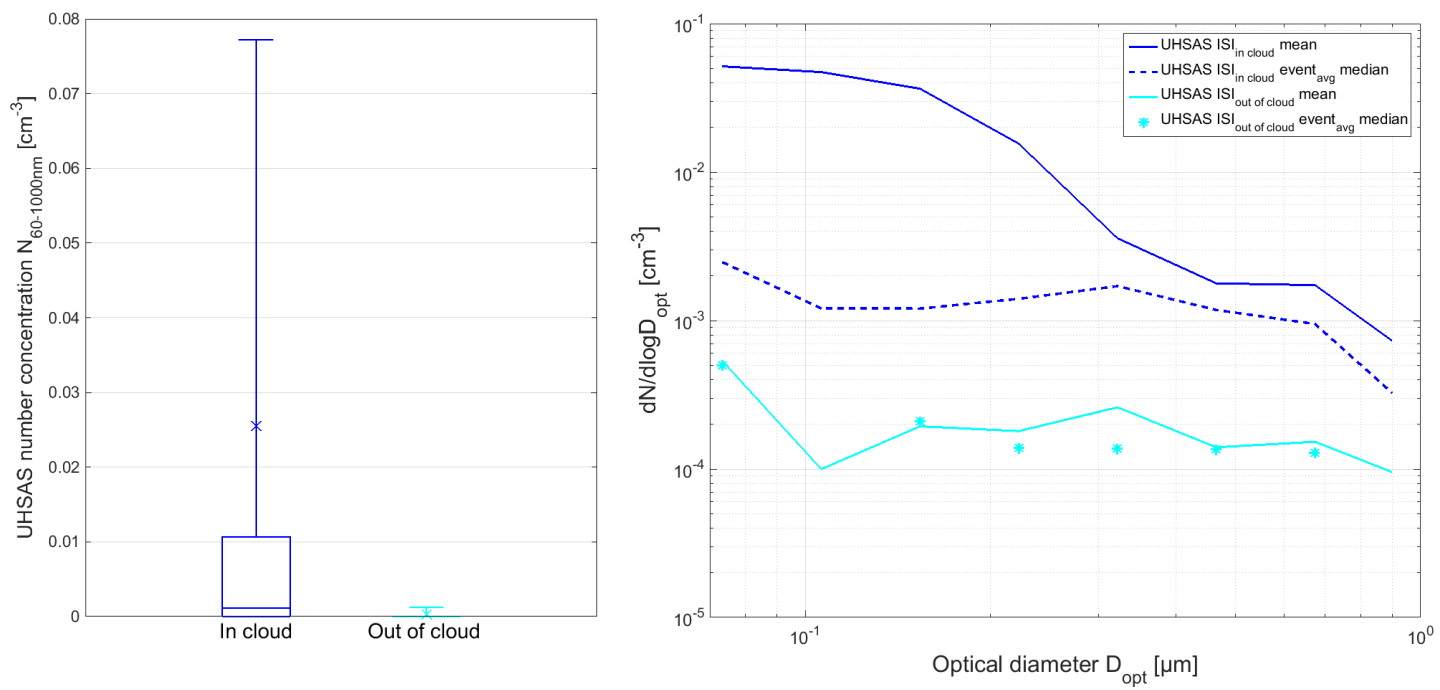

Figure 15. CLACE 2014 UHSAS measurements downstream of the ISI. The box plot (left panel) gives the mean (x), median (line in the box), 25th and 75th percentile (box edges), and the 10th and 90th percentiles (whiskers) of the 5 min UHSAS total concentration measurements in cloud vs. out of cloud during the campaign. The right panel shows in-cloud and out-of-cloud size distributions during the campaign. The mean in-cloud size distribution is given by the blue line, the mean out of cloud by the cyan line, the median of the cloud event means by the dashed blue line and the median of the clear event means by the asterisk symbol (where no symbol is visible, the median is 0 and thus not seen on a log-scale plot).

creased from 0 to $0.14 \mathrm{~L}^{-1}$ and the 75 th percentile from 2.6 to $3.9 \mathrm{~L}^{-1}$. The scattering patterns acquired with the PPD$2 \mathrm{~K}$ in 2014 (see Fig. 12 panel (d) for examples of randomly selected patterns) confirm the hypothesis that sublimation of ice crystals decreased greatly during CLACE 2014; the patterns show much less rounding of the ice crystals as compared to CLACE 2013 with columnar and irregular ice crystals frequently detected, as well as hexagonal plates.

\subsection{ISI ice residual measurements}

The high ice crystal losses in the droplet evaporation unit during CLACE 2013, and the resulting low counting statistics, greatly hamper the analysis of CLACE 2013 ice residual size distributions. Consequently, we present selected measurements of ice residuals from CLACE 2014, where ice crystal transmission was considerably higher due to the re-design of the droplet evaporation unit. Ice residual counts during CLACE 2014 were unfortunately also rather low, due to issues with the PCVI performance (ice residual counts were considerably lower than counts of particles larger than $5 \mu \mathrm{m}$ in the lower WELAS, implying losses in the PCVI. We speculate this could be due to misalignment of the PCVI nozzle, which could have occurred during installation of the PCVI. While misalignment does not have a negative effect on rejection of small particles (i.e. interstitial aerosol and droplet residues would still be removed from the sample flow), it has been shown to cause a substantial decrease in transmission efficiency if it should occur (Kulkarni et al., 2011). Nonetheless, the particles detected and characterized downstream of the ISI still represent residues of small ice crystals, albeit only a small fraction of all available. However, this is not an issue, except for counting statistics, as the loss processes for the ice crystals are expected to be independent of the IR properties. Figure 15 shows in-cloud and out-of-cloud UHSAS measurements downstream of the ISI. The box plot in the figure (left panel) shows that in-cloud counts are very low, but still they are much higher than the out-of-cloud UHSAS measurements, i.e. the background measurements. Similarly, the in-cloud vs. out-of-cloud UHSAS campaign median size distributions (right panel) show that, although both are similar in shape (both are relatively flat), the in-cloud distribution is much higher across all measured particle sizes than the out-of-cloud distribution. The average size distributions differ in shape somewhat (the in-cloud size distribution shows relatively much higher concentrations below $300 \mathrm{~nm}$ due to a single cloud event strongly influencing the average size distribution as compared to the median distribution) and also confirm that the in-cloud distribution is much higher than the out-of-cloud distribution. As the ratio of droplets to ice crystals among the hydrometeors detected by the PPD-2K is very low (as discussed in Sect. 3.2), and the hydrometeors transmitted are thus predominantly ice crystals, the stronger UHSAS signal in cloud compared to out of cloud is further proof that the ISI selectively extracts ice crystals, and the ice residuals contained within, in mixed-phase clouds. 

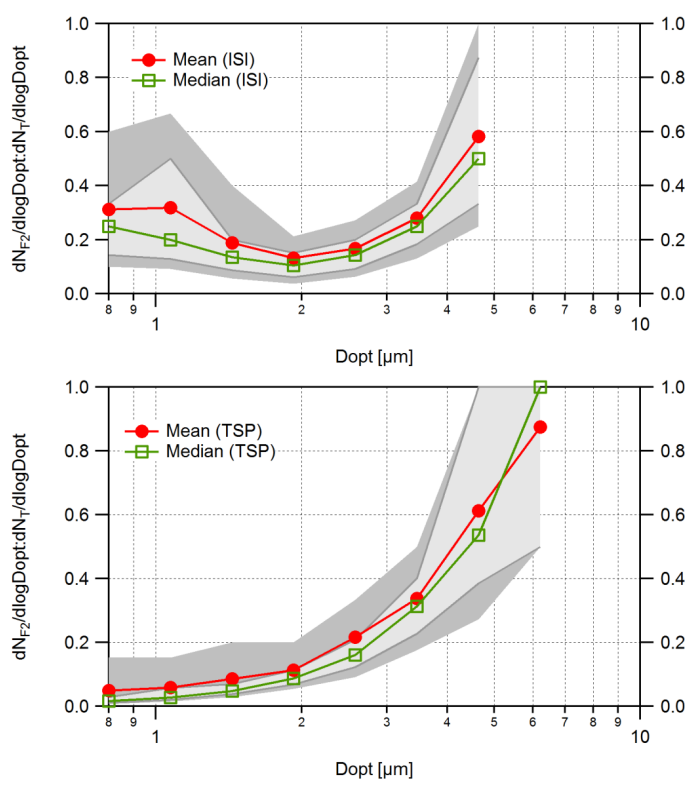
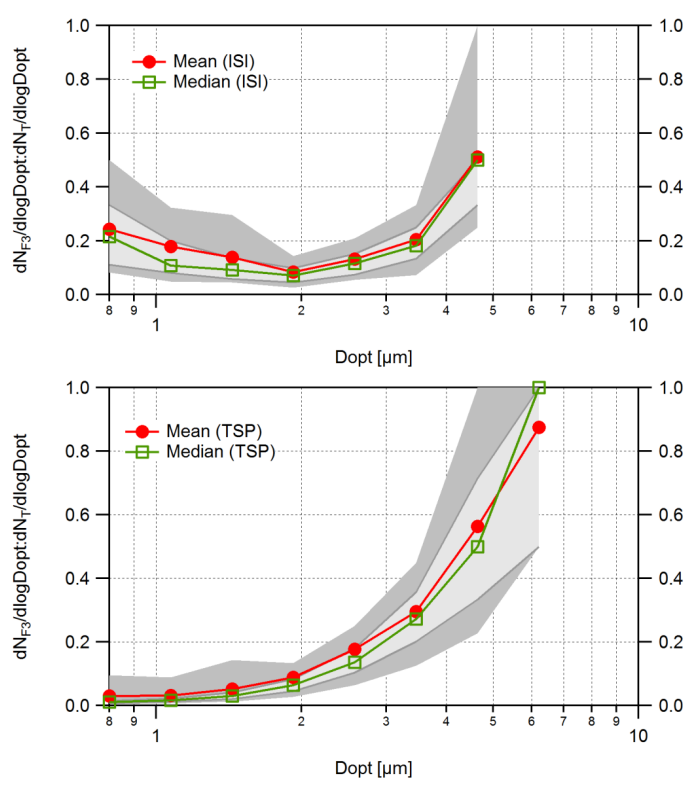

Figure 16. Ratio of fluorescent to all particles measured by the WIBS in two fluorescence channels (F2 in the left panels and F3 in the right panels) as a function of optical particle diameter during CLACE 2014 downstream of the ISI (upper panels) and the total inlet (lower panels) during a Saharan dust event on 18-19 February 2014. The median values are given by the green line, the mean values by the red line, the 25th and 75th percentiles by the light grey shaded area and the 10th and 90th percentiles by the dark grey shaded area.

\subsection{Ice residual characteristics during a Saharan dust event}

During CLACE 2014, on the 18-19 February 2014, a Saharan dust event lasting approximately $40 \mathrm{~h}$ was detected at the Jungfraujoch (see Collaud Coen et al. (2004) for a description of the SDE detection method). During the SDE, measurements were taken in cloud downstream of the ISI and the total inlet using the WIBS, which was switched between the two inlets.

For both inlets a ratio of fluorescent to all particles was calculated for the three fluorescence channels measured by the WIBS (shown in Fig. 16 are the ratios for fluorescence channels FL2 and FL3). The ratios, given by the green (median) and red (mean) lines in Fig. 16, are substantially higher for sub- $2 \mu \mathrm{m}$ particles downstream of the ISI (upper panels in Fig. 16), as compared to the total aerosol (lower panels in Fig. 16), which means there is enrichment of fluorescent particles in this size range. For particles between ca. 2 and $3.5 \mu \mathrm{m}$, the ratio is similar for both inlets. For larger particles the ratio is slightly higher for the total inlet measurements. However, the measurement uncertainty for particles above ca. $3.5 \mu \mathrm{m}$ is very high, as shown by the increasing spread of the 25th and 75th percentiles. It should be noted furthermore that for particles with aerodynamic diameters larger than $3 \mu \mathrm{m}$, the transmission efficiency through the PCVI increases strongly as the particle diameter increases, as seen in Fig. 9. Consequently, for particles larger than $3 \mu \mathrm{m}$, with increasing aerodynamic diameter of the sampled particles, an increasingly large fraction of the particles measured down- stream of the ISI during a Saharan dust event could be large dust particles which were not rejected by the PCVI. As a result, it is hard to make any meaningful statement regarding the properties of particles in this size range downstream of the ISI relative to the total inlet measurements.

The enrichment in sub- $2 \mu \mathrm{m}$ fluorescent particles downstream of the ISI is of great interest for two reasons. First, it confirms once again the operating principle of the ISI, demonstrating that the inlet does indeed have a selective nature and, therefore, that the properties of the measured particles are different from the bulk aerosol properties. Second, enrichment of fluorescent particles in the ice residuals strongly suggests the presence of biological material, which is known to be a very efficient catalyst for ice nucleation (Tobo et al., 2013). Long-range dust transport has been suggested to be an efficient pathway for dispersal of biological material (Hara and Zhang, 2012). A study by Izquierdo et al. (2011) found that herbaceous pollen from the Sahara region were transported on occasion to the Canary Islands, while Creamean et al. (2013) present evidence that dust and bioparticles transported from the Sahara and Asia serve as IN and contribute to formation of orographic precipitation over the western USA. The results from this study further support the hypothesis that biological material can be transported together with dust particles from north Africa and, as efficient ice nuclei, could contribute to formation of ice in mixedphase cloud conditions. 


\section{Conclusions}

The ISI, a novel inlet for the selective sampling of small (approximately 5 to $20 \mu \mathrm{m}$ in aerodynamic diameter) ice crystals in mixed-phase clouds, has been designed and developed. Separation of the small ice crystals from other particles found in a mixed-phase cloud (i.e. large crystals, droplets and interstitial particles) is achieved using a modular set of components. An important property of the droplet evaporation unit is that it allows for separation of the liquid and ice phase without physical impaction of the hydrometeors, thus avoiding potential artefacts from ice crystal break-up. In addition to extraction of ice residuals contained in the selectively sampled ice crystals, the ISI provides valuable cloud microphysical information by means of the optical particle spectrometers mounted within the inlet.

Prior to deployment in the field, the performance of the WELAS optical particle spectrometers and the transmission efficiency of the PCVI were characterized in the laboratory. Furthermore, the performance characteristics of the omnidirectional inlet and cyclone were calculated based on wellestablished theoretical models. The ISI was deployed during its first field experiment as part of the CLACE 2013 campaign at the high-altitude research station Jungfraujoch. The field campaign provided an opportunity for validation of the operating principle of the droplet evaporation unit. A comparison of SID-3 and ISI WELAS cloud microphysical measurements provides evidence that the ISI is able to sample ice crystals in mixed-phase cloud conditions. An analysis of hydrometeor size distributions measured by the WELAS sensors shows that droplets are removed very efficiently by the evaporation unit. This was confirmed based on PPD-2K scattering patterns which show that the dominating hydrometeors transmitted by the ISI are ice particles. Partial sublimation of ice crystals in the droplet evaporation unit was however found to take place. While this does not pose an issue for identification and characterization of ice residual particles, it does result in lower counting statistics, as well as hindering analysis of the microphysical properties of ice crystals with the PPD-2K downstream of the evaporation unit. Modifications in the design of the droplet evaporation unit prior to the CLACE 2014 campaign substantially improved the transmission efficiency. Ice residual measurements obtained during CLACE 2014 provided further proof of the ability of the ISI to selectively extract ice crystals in mixed-phase clouds. UVLIF measurements of aerosol during a Saharan dust event suggest the presence of bio-material. A first indication of enrichment of fluorescent particles, considered to be of biological origin based on their spectral signature, was found in sub$2 \mu \mathrm{m}$ ice residuals, suggesting their possible contribution to formation of ice during this period.

Acknowledgements. This project is funded by the Swiss National Science Foundation (grant 135356), the German Research Foundation (grant SCHN 1140/2-1), MeteoSwiss (GAW-CH program), the
European Research Council (grant 615922-BLACARAT) and the ACTRIS program (European Union Seventh Framework Program (FP7/2007-2013), grant 262254). The participation of S. Mertes was funded by the DFG priority program HALO (SPP 1294, grant ME 3534/1-2) and DFG research unit INUIT (grant STR 453/7-1). We thank the International Foundation High Altitude Research Stations Jungfraujoch and Gornergrat (HFSJG) for the opportunity to perform experiments on the Jungfraujoch. We would also like to thank G. Lloyd for providing the PVM data, L. Schenk for fruitful discussions and G. Wehrle for his help in setting up the ISI at the Jungfraujoch.

Edited by: D. Toohey

\section{References}

Bohren, C. F. and Huffman, D. R.: Absorption and Scattering of Light by Small Particles, Wiley-VCH Verlag GmbH, Weinheim, Germany, 1998.

Boulter, J. E., Cziczo, D. J., Middlebrook, A. M., Thomson, D. S., and Murphy, D. M.: Design and performance of a pumped counterflow virtual impactor, Aerosol Sci. Tech., 40, 969-976, doi:10.1080/02786820600840984, 2006.

Cai, Y., Montague, D. C., Mooiweer-Bryan, W., and Deshler, T.: Performance characteristics of the ultra high sensitivity aerosol spectrometer for particles between 55 and $800 \mathrm{~nm}$ : Laboratory and field studies, J. Aerosol Sci., 39, 759-769, doi:10.1016/j.jaerosci.2008.04.007, 2008.

Cantrell, W. and Heymsfield, A.: Production of ice in tropospheric clouds: a review, B. Am. Meteorol. Soc., 86, 795-807, doi:10.1175/BAMS-86-6-795, 2005.

Chou, C., Stetzer, O., Weingartner, E., Jurányi, Z., Kanji, Z. A., and Lohmann, U.: Ice nuclei properties within a Saharan dust event at the Jungfraujoch in the Swiss Alps, Atmos. Chem. Phys., 11, 4725-4738, doi:10.5194/acp-11-4725-2011, 2011.

Choularton, T. W., Bower, K. N., Weingartner, E., Crawford, I., Coe, H., Gallagher, M. W., Flynn, M., Crosier, J., Connolly, P., Targino, A., Alfarra, M. R., Baltensperger, U., Sjogren, S., Verheggen, B., Cozic, J., and Gysel, M.: The influence of small aerosol particles on the properties of water and ice clouds, Farad. Discuss., 137, 205-22, doi:10.1039/B702722M, 2008.

Collaud Coen, M., Weingartner, E., Schaub, D., Hueglin, C., Corrigan, C., Henning, S., Schwikowski, M., and Baltensperger, U.: Saharan dust events at the Jungfraujoch: detection by wavelength dependence of the single scattering albedo and first climatology analysis, Atmos. Chem. Phys., 4, 2465-2480, doi:10.5194/acp4-2465-2004, 2004.

Cozic, J., Mertes, S., Verheggen, B., Cziczo, D. J., Gallavardin, S. J., Walter, S., Baltensperger, U., and Weingartner, E.: Black carbon enrichment in atmospheric ice particle residuals observed in lower tropospheric mixed phase clouds, J. Geophys. Res.Atmos., 113, D15209, doi:10.1029/2007JD009266, 2008.

Creamean, J. M., Suski, K. J., Rosenfeld, D., Cazorla, A., DeMott, P. J., Sullivan, R. C., White, A. B., Ralph, F. M., Minnis, P., Comstock, J. M., Tomlinson, J. M., and Prather, K. A.: Dust and biological aerosols from the Sahara and Asia influence precipitation in the western U.S., Science, 339, 1572-1578, doi:10.1126/science.1227279, 2013. 
Cziczo, D. J., Froyd, K. D., Hoose, C., Jensen, E. J., Diao, M., Zondlo, M. A., Smith, J. B., Twohy, C. H., and Murphy, D. M.: Clarifying the dominant sources and mechanisms of cirrus cloud formation, Science, 340, 1320-1324, doi:10.1126/science.1234145, 2013.

Eames, I., Marr, N., and Sabir, H.: The evaporation coefficient of water: a review, Int. J. Heat Mass Tran., 40, 2963-2973, doi:10.1016/S0017-9310(96)00339-0, 1997.

Fukuta, N. and Walter, L. A.: Kinetics of hydrometeor growth from a vapor-spherical model, J. Atmos. Sci., 27, 1160-1172, doi:10.1175/1520-0469(1970)027<1160:KOHGFA>2.0.CO;2, 1970.

Glen, A. and Brooks, S. D.: A new method for measuring optical scattering properties of atmospherically relevant dusts using the Cloud and Aerosol Spectrometer with Polarization (CASPOL), Atmos. Chem. Phys., 13, 1345-1356, doi:10.5194/acp-13-13452013, 2013.

Hara, K. and Zhang, D.: Bacterial abundance and viability in long-range transported dust, Atmos. Environ., 47, 20-25, doi:10.1016/j.atmosenv.2011.11.050, 2012.

Heim, M., Mullins, B. J., Umhauer, H., and Kasper, G.: Performance evaluation of three optical particle counters with an efficient "multimodal" calibration method, J. Aerosol Sci., 39, 1019-1031, doi:10.1016/j.jaerosci.2008.07.006, 2008.

Heymsfield, A. J. and Iaquinta, J.: Cirrus crystal terminal velocities, J. Atmos. Sci., 57, 916-938, doi:10.1175/15200469(2000)057<0916:CCTV>2.0.CO;2, 2000.

Izquierdo, R., Belmonte, J., Avila, A., Alarcón, M., Cuevas, E., and Alonso-Pérez, S.: Source areas and long-range transport of pollen from continental land to Tenerife (Canary Islands), Int. J. Biometeorol., 55, 67-85, doi:10.1007/s00484-010-0309-1, 2011.

Kärcher, B. and Basko, M. M.: Trapping of trace gases in growing ice crystals, J. Geophys. Res.-Atmos., 109, D22204, doi:10.1029/2004JD005254, 2004.

Kaye, P. H., Hirst, E., Greenaway, R. S., Ulanowski, Z., Hesse, E., DeMott, P. J., Saunders, C., and Connolly, P.: Classifying atmospheric ice crystals by spatial light scattering, Opt. Lett., 33, 1545-1547, doi:10.1364/OL.33.001545, 2008.

Kenny, L. and Gussman, R.: Characterization and modelling of a family of cyclone aerosol preseparators, J. Aerosol Sci., 28, 677688, doi:10.1016/S0021-8502(96)00455-7, 1997.

Kenny, L. and Gussman, R.: A direct approach to the design of cyclones for aerosol-monitoring applications, J. Aerosol Sci., 31, 1407-1420, doi:10.1016/S0021-8502(00)00047-1, 2000.

Kreidenweis, S. M., Walcek, C. J., Feingold, G., Gong, W., Jacobson, M. Z., Kim, C.-H., Liu, X., Penner, J. E., Nenes, A., and Seinfeld, J. H.: Modification of aerosol mass and size distribution due to aqueous-phase SO2 oxidation in clouds: comparisons of several models, J. Geophys. Res.-Atmos., 108, 4213, doi:10.1029/2002JD002697, 2003.

Kulkarni, G., Pekour, M., Afchine, A., Murphy, D. M., and Cziczo, D. J.: Comparison of experimental and numerical studies of the performance characteristics of a pumped counterflow virtual impactor, Aerosol Sci. Tech., 45, 382-392, doi:10.1080/02786826.2010.539291, 2011.

Laaksonen, A., Vesala, T., Kulmala, M., Winkler, P. M., and Wagner, P. E.: Commentary on cloud modelling and the mass accommodation coefficient of water, Atmos. Chem. Phys., 5, 461-464, doi:10.5194/acp-5-461-2005, 2005.
Lloyd, G., Choularton, T. W., Bower, K. N., Gallagher, M. W., Connolly, P. J., Flynn, M., Farrington, R., Crosier, J., Schlenczek, O., Fugal, J., and Henneberger, J.: The origins of ice crystals measured in mixed phase clouds at High-Alpine site Jungfraujoch, Atmos. Chem. Phys. Discuss., 15, 18181-18224, doi:10.5194/acpd-15-18181-2015, 2015.

Lohmann, U.: A glaciation indirect aerosol effect caused by soot aerosols, Geophys. Res. Lett., 29, 4, 11-1-11-4, doi:10.1029/2001GL014357, 2002.

Lohmann, U. and Feichter, J.: Global indirect aerosol effects: a review, Atmos. Chem. Phys., 5, 715-737, doi:10.5194/acp-5-7152005, 2005.

Lowe, P. R. and Ficke, J. M.: The computation of saturation vapor pressure, Technical Paper 4-74, Tech. rep., Environmental Prediction Research Facility, Naval Postgraduate School, Monterey, CA, USA, 1974.

Marécal, V., Pirre, M., Rivière, E. D., Pouvesle, N., Crowley, J. N., Freitas, S. R., and Longo, K. M.: Modelling the reversible uptake of chemical species in the gas phase by ice particles formed in a convective cloud, Atmos. Chem. Phys., 10, 4977-5000, doi:10.5194/acp-10-4977-2010, 2010.

Marek, R. and Straub, J.: Analysis of the evaporation coefficient and the condensation coefficient of water, Int. J. Heat Mass Tran., 44, 39-53, doi:10.1016/S0017-9310(00)00086-7, 2001.

McFarlane, S. A. and Marchand, R. T.: Analysis of ice crystal habits derived from MISR and MODIS observations over the ARM Southern Great Plains site, J. Geophys. Res.-Atmos., 113, doi:10.1029/2007JD009191, 2008.

Mertes, S., Verheggen, B., Walter, S., Connolly, P., Ebert, M., Schneider, J., Bower, K. N., Cozic, J., Weinbruch, S., Baltensperger, U., and Weingartner, E.: Counterflow virtual impactor based collection of small ice particles in mixed-phase clouds for the physico-chemical characterization of tropospheric ice nuclei: sampler description and first case study, Aerosol Sci. Tech., 41, 848-864, doi:10.1080/02786820701501881, 2007.

Möhler, O., Büttner, S., Linke, C., Schnaiter, M., Saathoff, H., Stetzer, O., Wagner, R., Krämer, M., Mangold, A., Ebert, V., and Schurath, U.: Effect of sulfuric acid coating on heterogeneous ice nucleation by soot aerosol particles, J. Geophys. Res.-Atmos. 110, D11210, doi:10.1029/2004JD005169, 2005.

Mosimann, L., Weingartner, E., and Waldvogel, A.: An analysis of accreted drop sizes and mass on rimed snow crystals, J. Atmos. Sci., 51, 1548-1558, doi:10.1175/15200469(1994)051<1548:AAOADS>2.0.CO;2, 1994.

Myhre, G., Shindell, D., Bréon, F.-M., Collins, W., Fuglestvedt, J., Huang, J., Koch, D., Lamarque, J.-F., Lee, D., Mendoza, B., Nakajima, T., Robock, A., Stephens, G., Takemura, T., and Zhang, H.: Anthropogenic and Natural Radiative Forcing, in: Climate Change 2013: The Physical Science Basis. Contribution of Working Group I to the Fifth Assessment Report of the Intergovernmental Panel on Climate Change, chap. 8, 659-740, Cambridge University Press, Cambridge, UK and New York, NY, USA, 2013.

Nelson, J.: Sublimation of ice crystals, J. Atmos. Sci., 55, 910-919, doi:10.1175/1520-0469(1998)055<0910:SOIC>2.0.CO;2, 1998.

Noone, K. J., Hansson, H.-C., and Mallant, R. K.: Droplet sampling from crosswinds: An inlet efficiency calibration, J. Aerosol Sci., 23, 153-164, doi:10.1016/0021-8502(92)90051-V, 1992. 
Pekour, M. S. and Cziczo, D. J.: Wake capture, particle breakup, and other artifacts associated with counterflow virtual impaction, Aerosol Sci. Tech., 45, 758-764, doi:10.1080/02786826.2011.558942, 2011.

Penner, J. E.: Climate change: the cloud conundrum, Nature, 432, 962-963, doi:10.1038/432962a, 2004.

Pfalzgraff, W. C., Hulscher, R. M., and Neshyba, S. P.: Scanning electron microscopy and molecular dynamics of surfaces of growing and ablating hexagonal ice crystals, Atmos. Chem. Phys., 10, 2927-2935, doi:10.5194/acp-10-2927-2010, 2010.

Pound, G. M.: Selected values of evaporation and condensation coefficients for simple substances, J. Phys. Chem. Ref. Data, 1, 135-146, doi:10.1063/1.3253096, 1972.

Prenni, A. J., DeMott, P. J., Twohy, C., Poellot, M. R., Kreidenweis, S. M., Rogers, D. C., Brooks, S. D., Richardson, M. S., and Heymsfield, A. J.: Examinations of ice formation processes in Florida cumuli using ice nuclei measurements of anvil ice crystal particle residues, J. Geophys. Res.-Atmos., 112, D10221, doi:10.1029/2006JD007549, 2007.

Pruppacher, H. R. and Klett, J. D.: Microphysics of Clouds and Precipitation, 2nd ed., Kluwer Academic Publishers, Dordrecht, the Netherlands, 1997.

Rosati, B., Wehrle, G., Gysel, M., Zieger, P., Baltensperger, U., and Weingartner, E.: The white-light humidified optical particle spectrometer (WHOPS) - a novel airborne system to characterize aerosol hygroscopicity, Atmos. Meas. Tech., 8, 921-939, doi:10.5194/amt-8-921-2015, 2015.

Sassen, K., Knight, N. C., Takano, Y., and Heymsfield, A. J.: Effects of ice-crystal structure on halo formation: cirrus cloud experimental and ray-tracing modeling studies, Appl. Opt., 33, 45904601, doi:10.1364/AO.33.004590, 1994.

Schenk, L. P., Mertes, S., Kästner, U., Frank, F., Nillius, B., Bundke, U., Rose, D., Schmidt, S., Schneider, J., Worringen, A., Kandler, K., Bukowiecki, N., Ebert, M., Curtius, J., and Stratmann, F.: Characterization and first results of an ice nucleating particle measurement system based on counterflow virtual impactor technique, Atmos. Meas. Tech. Discuss., 7, 10585-10617, doi:10.5194/amtd-7-10585-2014, 2014.

Schmidt, S., Schneider, J., Klimach, T., Mertes, S., Schenk, L. P., Curtius, J., Kupiszewski, P., Hammer, E., Vochezer, P., Lloyd, G., Ebert, M., Kandler, K., Weinbruch, S., and Borrmann, S.: In-situ single submicron particle composition analysis of ice residuals from mountain-top mixed-phase clouds in Central Europe, 15, 4677-4724, doi:10.5194/acpd-15-4677-2015, 2015.

Seinfeld, J. H. and Pandis, S. N.: Atmospheric Chemistry and Physics: From Air Pollution to Climate Change, 2nd Edition, John Wiley \& Sons, Inc., Hoboken, NJ, USA, 2006.

Shaw, R. A. and Lamb, D.: Experimental determination of the thermal accommodation and condensation coefficients of water, J. Chem. Phys, 111, 10659-10663, doi:10.1063/1.480419, 1999.

Sun, Z. and Shine, K. P.: Studies of the radiative properties of ice and mixed-phase clouds, Q. J. Roy. Meteor. Soc., 120, 111-137, doi:10.1002/qj.49712051508, 1994.
Tobo, Y., Prenni, A. J., DeMott, P. J., Huffman, J. A., McCluskey, C. S., Tian, G., Pöhlker, C., Pöschl, U., and Kreidenweis, S. M.: Biological aerosol particles as a key determinant of ice nuclei populations in a forest ecosystem, J. Geophys. Res.-Atmos., 118, 10100-10110, doi:10.1002/jgrd.50801, 2013.

Toprak, E. and Schnaiter, M.: Fluorescent biological aerosol particles measured with the Waveband Integrated Bioaerosol Sensor WIBS-4: laboratory tests combined with a one year field study, Atmos. Chem. Phys., 13, 225-243, doi:10.5194/acp-13225-2013, 2013.

Toprak, E. and Schnaiter, M.: Measurement of biological particles during Saharan dust events at Jungfraujoch, Atmos. Chem. Phys., in prep., 2015.

Twohy, C. H. and Poellot, M. R.: Chemical characteristics of ice residual nuclei in anvil cirrus clouds: evidence for homogeneous and heterogeneous ice formation, Atmos. Chem. Phys., 5, 22892297, doi:10.5194/acp-5-2289-2005, 2005.

Ulanowski, Z., Kaye, P. H., Hirst, E., Greenaway, R. S., Cotton, R. J., Hesse, E., and Collier, C. T.: Incidence of rough and irregular atmospheric ice particles from Small Ice Detector 3 measurements, Atmos. Chem. Phys., 14, 1649-1662, doi:10.5194/acp14-1649-2014, 2014.

Verheggen, B., Cozic, J., Weingartner, E., Bower, K., Mertes, S., Connolly, P., Gallagher, M., Flynn, M., Choularton, T., and Baltensperger, U.: Aerosol partitioning between the interstitial and the condensed phase in mixed-phase clouds, J. Geophys. Res.Atmos., 112, doi:10.1029/2007JD008714, 2007.

Vincent, J. H.: Aerosol Sampling: Science, Standards, Instrumentation and Applications, John Wiley \& Sons, Ltd, Chichester, UK, 2007.

Vochezer, P., Järvinen, E., Wagner, R., Kupiszewski, P., Leisner, T., and Schnaiter, M.: In situ characterization of mixed phase clouds using the Small Ice Detector and the Particle Phase Discriminator, Atmos. Meas. Tech. Discuss., 8, 6511-6558, doi:10.5194/amtd-8-6511-2015, 2015.

von der Weiden, S.-L., Drewnick, F., and Borrmann, S.: Particle Loss Calculator - a new software tool for the assessment of the performance of aerosol inlet systems, Atmos. Meas. Tech., 2, 479-494, doi:10.5194/amt-2-479-2009, 2009.

Wang, L.: Theoretical study of cyclone design, Ph.D. thesis, Texas A\&M University, 2004.

Weingartner, E., Nyeki, S., and Baltensperger, U.: Seasonal and diurnal variation of aerosol size distributions $(10<D<750 \mathrm{~nm})$ at a high-alpine site (Jungfraujoch $3580 \mathrm{~m}$ a.s.1.), J. Geophys. Res.Atmos., 104, 26809-26820, doi:10.1029/1999JD900170, 1999.

Worringen, A., Kandler, K., Benker, N., Dirsch, T., Mertes, S., Schenk, L., Kästner, U., Frank, F., Nillius, B., Bundke, U., Rose, D., Curtius, J., Kupiszewski, P., Weingartner, E., Vochezer, P., Schneider, J., Schmidt, S., Weinbruch, S., and Ebert, M.: Singleparticle characterization of ice-nucleating particles and ice particle residuals sampled by three different techniques, 15, 41614178, doi:10.5194/acp-15-4161-2015, 2015. 